\title{
A 4-18-GHz Reconfigurable RF MEMS Matching Network For Power Amplifier Applications
}

\author{
Tauno Vähä-Heikkilä, ${ }^{1,2}$ Gabriel M. Rebeiz ${ }^{1}$ \\ ${ }^{1}$ The University of Michigan, Electrical Engineering and Computer Science Department, \\ Ann Arbor, MI, 48109-2122 \\ 2 VTT Information Technology, P.O. BOX 12021,02044 VTT, Finland \\ Received 24 September 2003; accepted 19 February 2004
}

\begin{abstract}
We have developed a novel reconfigurable matching network based on the loaded-line technique. The network is composed of $N$-switched capacitors $(N=4-8)$ with a capacitance ratio of 4-5:1 and is suitable for power amplifiers at 4-18 GHz, or as an impedance tuner for noise parameter and load-pull measurements at 10-28 GHz. The networks are very small, and offer better performance than double or triple stub matching networks. Extensive loss analysis indicates that the 8-element network has a loss of $0.5 \mathrm{~dB}$ at 4-12 GHz, and less than $1.5 \mathrm{~dB}$ at $18 \mathrm{GHz}$, even when matching a $10 \Omega$ output impedance to a $50 \Omega$ load. As expected, the 4-element matching network has about half the loss of the 8-element network, but with much less impedance coverage. Both networks were simulated and measured in high VSWR conditions and can handle at least $500 \mathrm{~mW}$ of RF power at 4-18 GHz. The application areas are in phased array antennas, reconfigurable power amplifiers, and wideband noise-parameter and load-pull measurement systems. () 2004 Wiley Periodicals, Inc. Int J RF and Microwave CAE 14: 356-372, 2004.
\end{abstract}

Keywords: RF MEMS; reconfigurable networks; impedance tuner; matching network; loaded-line; phased arrays; load-pull; noise parameters

\section{INTRODUCTION}

Power amplifiers (PAs) with 1-2-W output power and a $5-\mathrm{V}$ power supply have an output impedance of $10 \Omega-20 \Omega$, and are mismatched in $50 \Omega$ systems. Therefore, it is imperative that a low-loss impedance matching network be used to ensure optimum power transfer between the PA and the antenna (Fig. 1). The matching network should be flexible enough to accommodate a changing load impedance or a changing PA output impedance. This is a common problem, for example, in multiband wireless networks where the antennas are placed close to walls or obstacles. An-

Correspondence to: T. Vähä-Heikkilä; email: heikkila@ eecs.umich.edu

Published online in Wiley InterScience (www.interscience. wiley.com). DOI 10.1002/mmce.20021 other application is in phased arrays where the active input antenna impedance changes with scanning angles and operating frequency. Also, the PA output impedance can change versus frequency due to gain degradation over extended operation times.

A standard narrowband matching network is the CLC network with variable capacitors [1]. Such a network can match a wide range of impedances, but suffers from a narrowband response (single or dualfrequency bands). For wider frequency coverage, one can use reconfigurable networks based on the double-stub or triple-stub tuners [2,3]. These networks offer excellent performance, but are quite large and employ a large number of MEMS switches (or varactors). Also, depending on the design, they can have a substantial loss component (0.5-3-dB loss), thus resulting in a reduced Smith chart coverage. 

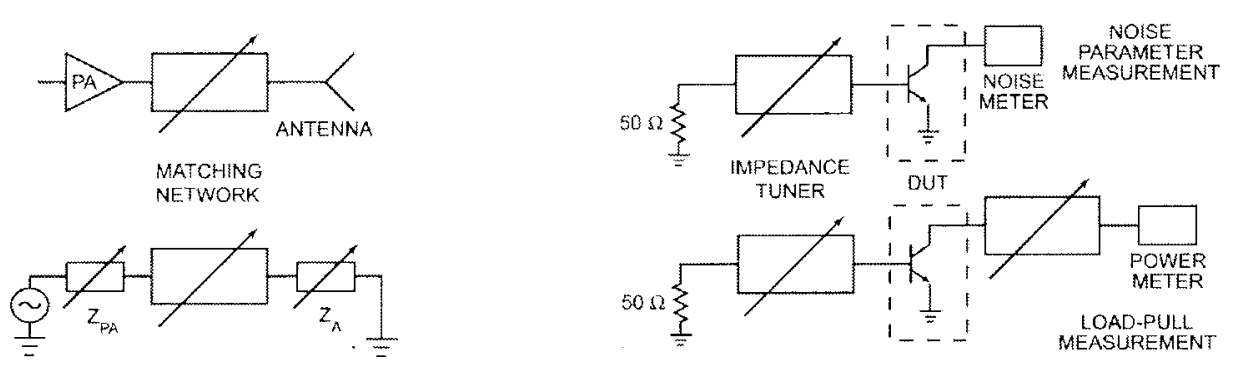

Figure 1. A reconfigurable matching network used between a power amplifier and a radiating antenna, or as an impedance tuner in noise or load-pull measurements.

In this work, we present a novel matching network capable of very wideband PA matching $(4-18 \mathrm{GHz})$, and with low loss. The network is based on a loaded transmission-line with $N$ switched capacitors. The article analyses in detail the loss of matching networks in non-50 $\Omega$ systems, taking in to consideration that they are measured solely using $50 \Omega S$-parameter setups. This work also presents simulations and measurements of the power handling and intermodulation distortion of the novel matching network. The reconfigurable network can also be used in noise and loadpull measurement setups. In this case, the network loss is less of a concern, and the important characteristic is that a large range of impedance be synthesized at the transistor input. This article shows that the proposed network can work over a 3:1 frequency range for these applications.

\section{DESIGN AND FABRICATION}

\section{A. Design of the Reconfigurable Loaded-Line}

It is well known that the phase velocity and impedance of a transmission line can be changed by capacitive loading. This fact has been used in distributed transmission-line (DMTL) MEMS phase shifters [1, $4,5]$ and in tunable filters [6]. The loaded-line idea can also be applied to reconfigurable matching networks: a transmission-line is loaded with $\mathrm{N}$-switched MEMS capacitors, each having a capacitance $C_{U}$ (upstate position) and $C_{D}$ (down-state position), and the line impedance is chosen to be approximately $50 \Omega$ when the MEMS capacitors are in the up-state position (Fig. 2). The capacitance ratio is chosen anywhere from $3: 1$ to $8: 1$, depending upon the design. When a MEMS capacitor is actuated to the down-state position, the loading on the t-line increases, thus resulting in a localized low impedance and a high effective dielectric constant (around the region of the MEMS capacitor). Since the loading is increasingly capacitive with more MEMS switches being actuated,

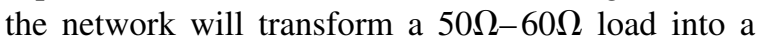
low-input impedance (or vice versa, due to reciprocity), and the higher the capacitive loading, the lower the input impedance. A 4- to 8-element design results in 16 to 256 different impedance points on the Smith chart, and the distributed nature of the design ensures wideband-frequency coverage. Also, at high frequency and due to the varying electrical length of the loaded t-line, when the switched capacitors are actuated, the impedance coverage covers the entire Smith chart and not only the low impedance region.

Many different parameters can be optimized in the loaded-line network. In general, a larger number of switched capacitors yield more wideband operation and better Smith chart coverage. However, this also results in increased component size and loss, thus the smallest $N$ must be chosen to meet the specific application. The highest frequency of operation is limited by the Bragg frequency (see below) of the loaded line, and the lowest impedance which can be matched to $50 \Omega$ is dependent on the loading capacitance (see section III). A closed-form design technique has not been found, because the location, electrical length, and loaded-line impedance change with the actuation of the MEMS switched capacitors; therefore, Agilent ADS [7] is used extensively for choosing $C_{U}, C_{D}, s$, and the number of capacitors. The design is amazingly robust, and a capacitance or a separation change of $\pm 30 \%$ will not affect the performance much, especially if $N=6-8$.

\section{B. Basic Analysis and Model Fitting}

The impedance $\left(Z_{L}\right)$ and effective dielectric constant $\left(\varepsilon_{\text {reff-L }}\right)$ of a capacitively loaded t-line is calculated using [8]:

$$
K=1+\frac{c Z_{0} C}{s \sqrt{\varepsilon_{\mathrm{reff}}}},
$$




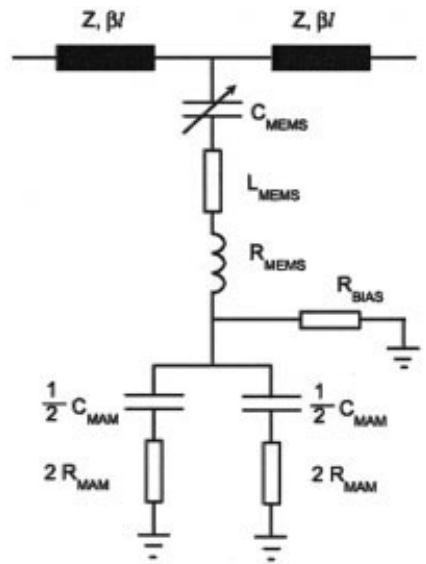

(a)

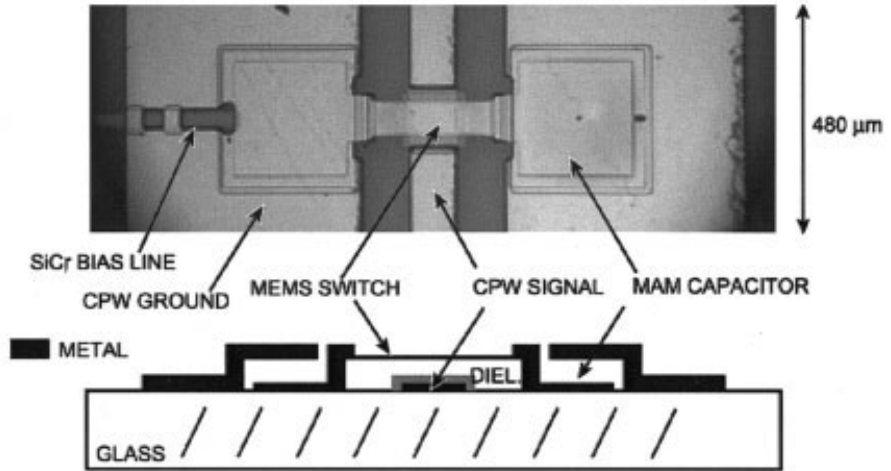

(b)

Figure 2. (a) Equivalent circuit, and (b) picture and cross-sectional view of a switched MEMS capacitor. The CPW signal line is DC grounded. This represents one cell in the reconfigurable loaded-line matching network.

$$
\begin{gathered}
\varepsilon_{\text {reff_L } L}=\varepsilon_{\text {reff }} K, \\
Z_{L}=\mathrm{Z}_{U}, Z_{D}=Z_{0} / \sqrt{K},
\end{gathered}
$$

where $c$ is the speed of the light in free space, $C$ is the capacitance of the switched capacitor $\left(C_{U}, C_{D}\right), \varepsilon_{\text {reff }}$ is the effective dielectric constant of the unloaded line, and $\mathrm{s}$ is the period of the loading structure $(s=480$ $\mu \mathrm{m}$ ). In this design (Fig. 3), the loaded line characteristics are $Z_{U}=45 \Omega$ and $\varepsilon_{\text {reff- } u}=10$, and $Z_{D}=23 \Omega$ and $\varepsilon_{\text {reff-D }}=38.2$, when the MEMS switches are in the up-state and down-state positions, respectively. The impedance in the up-state was designed to be $50 \Omega$ but is lower since the MEMS bridges are curved down resulting in a larger loading capacitance.

The Bragg frequency is calculated using [4]:

$$
f_{\mathrm{B}}=\frac{c Z_{L}}{\pi s Z_{0} \sqrt{\varepsilon_{\text {reff }}}}
$$

and is $62.8 \mathrm{GHz}$ and $32.2 \mathrm{GHz}$ in the up-state and down-state positions, respectively. In general, it is good to have a relatively high Bragg frequency in order to obtain good operation over a wide-frequency range. The measured and simulated $S$-parameters for the 8-element matching network are shown in Figure 4, and Agilent ADS is used for fitting the values of the switched MEMS capacitor (see Fig. 2(a) and Table 1).

\section{Fabrication}

The MEMS switched capacitor is fabricated using a series combination of a capacitive RF MEMS switch (with a capacitance ratio of 10-30:1) and fixed metalinsulator-metal (MIM) or metal-air-metal (MAM) capacitors. The down-state capacitance is mostly determined by the MIM (or MAM) capacitor (300-900 fF for X-band operation), while the up-state capacitance is set by the MEMS switch (70-80 fF). In this work, MAM capacitors are used for high- $Q$ performance. Figure 2 shows a fabricated MEMS switched capacitor, and is based on a coplanar waveguide (CPW) transmission line with dimensions $100 / 100 / 100 \mu \mathrm{m}$ on a $500 \mu \mathrm{m}$ glass substrate (see Table 1). The dimensions of the MEMS switch are $280 \mu \mathrm{m} \times 80 \mu \mathrm{m}$ and the area of each MAM capacitor is $240 \mu \mathrm{m} \times 235$ $\mu \mathrm{m}$. The MEMS bridge is fabricated using a $0.8 \mu \mathrm{m}$ thick gold membrane suspended $1.1 \mu \mathrm{m}$ above the t-line, and a $3500 \AA$ silicon-nitride dielectric interlayer. The fabrication process is based on standard
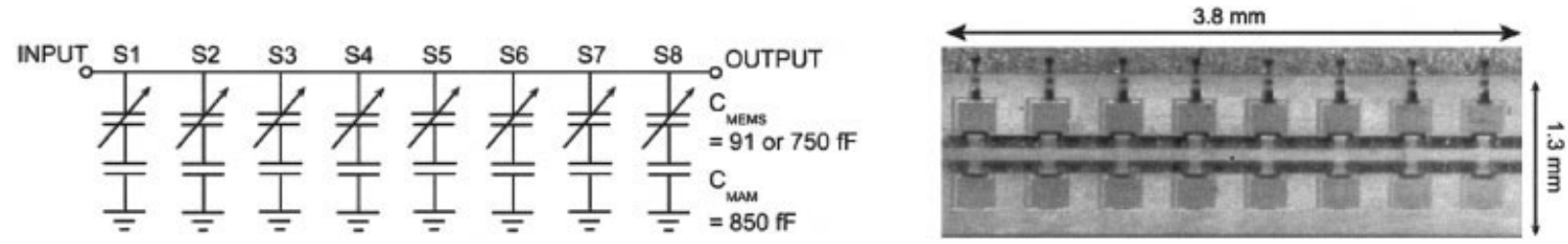

Figure 3. Circuit diagram and picture of the eight-element reconfigurable matching network. 

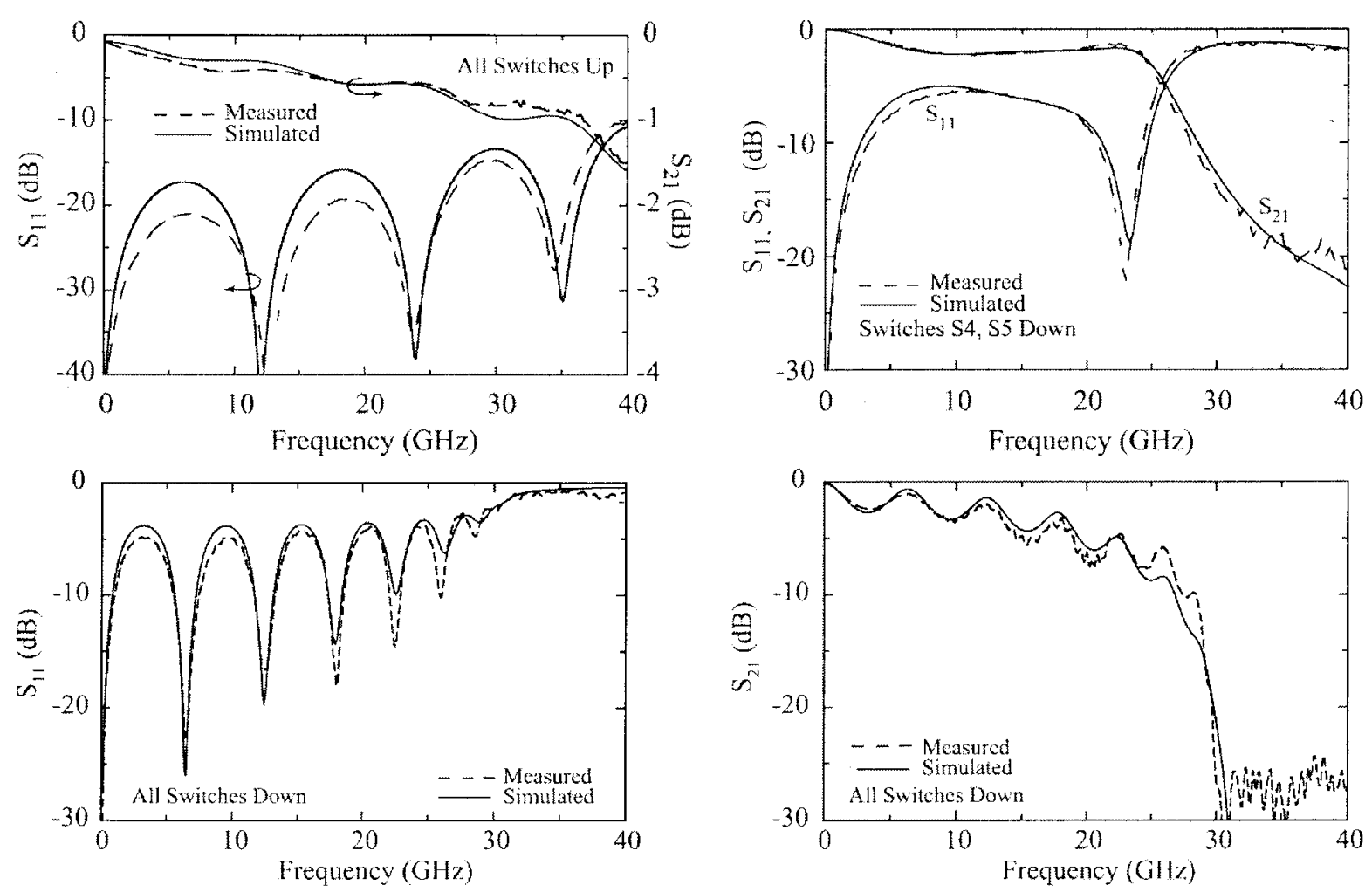

Figure 4. Measured and simulated $S$-parameters for the 8-switched capacitor reconfigurable MEMS network with different switch combinations.

techniques and is described in [9]. Polymethylmethacrylate (PMMA) is used as a sacrificial layer under the switches and MAM capacitors, and is patterned using oxygen plasma in a reactive ion etcher (RIE). The circuit is electroplated to $3 \mu \mathrm{m}$-thick (except the MEMS bridges) to reduce the t-line and MAM capacitor loss. $\mathrm{SiCr}$ bias lines with resistance of $700 \Omega /$

TABLE I. Measured T-Line Values From the TRL Calibration (Top), Fitted Values for the Switched MEMS Capacitor (Middle), and Loaded-Line Characteristics (Bottom)

\begin{tabular}{lc}
\hline$\varepsilon_{r}$ & 4.6 \\
$Z_{\mathrm{O}}(\Omega)$ & 86.2 \\
$\varepsilon_{\text {reff }}$ & 2.72 \\
$\alpha(\mathrm{dB} / \mathrm{cm}), 10 / 20 \mathrm{GHz}$ & $0.35 / 0.52$ \\
$C_{M E M S}: C_{\mathrm{UP}}(\mathrm{fF})$ & 91 \\
$C_{M E M S}: C_{\text {DOWN }}(\mathrm{fF})$ & 750 \\
$R_{B I A S}(\mathrm{k} \Omega)$ & $>3$ \\
$L_{M E M S}(\mathrm{pH})$ & 9.5 \\
$R_{M E M S}+R_{\mathrm{MAM}}(\Omega)$ & 0.6 \\
$C_{M A M}(\mathrm{fF})$ & 850 \\
$s(\mu \mathrm{m})$ & 480 \\
$Z_{U}(\Omega), \varepsilon_{\text {reff_U }}$ & 45,10 \\
$Z_{D}(\Omega), \varepsilon_{\text {reff_D }}$ & 23,38 \\
\hline
\end{tabular}

square are used for actuating the MEMS switch. The measured pull-down voltage was $15-17 \mathrm{~V}$, and an actuation voltage of $35 \mathrm{~V}$ was used for obtaining an excellent metal-to-dielectric coverage in the downstate position. The estimated spring constant is $k=$ $40-50 \mathrm{~N} / \mathrm{m}$ from the standard pull-down equation [10]. The estimated residual stress is $\sigma=50-60 \mathrm{MPa}$ using the formulas in [10].

The measured capacitance ratio of the RF MEMS switch is only 8:1 due to its low height and thick silicon-nitride layer (see Table 1), and the fixed MAM capacitor is $850 \mathrm{fF}$. This results in $C_{U}=81.2 \mathrm{fF}, C_{D}$ $=398 \mathrm{fF}$ and a capacitance ratio 4.9:1. The quality factor of the MEMS switched capacitor is calculated using $Q=\left(2 \pi f C\left(R_{M E M S}+R_{M A M}\right)\right)^{-1}$ and at $12 \mathrm{GHz}$ results in $Q_{U}=272\left(C_{U}=81.2 \mathrm{fF}, X=-j 163 \Omega\right)$ and $Q_{D}=56\left(C_{D}=398 \mathrm{fF}, X=-j 33.3 \Omega\right)$ in the up-state and down-state positions, respectively.

\section{IMPEDANCE COVERAGE}

\section{A. Simulations and Measurements}

The measured and simulated input impedances of the 8 -element matching network are presented in Figure 5 


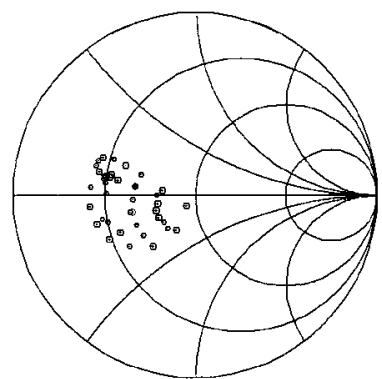

Measured 4.1 GHz

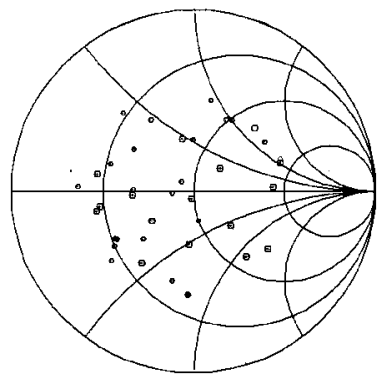

Measured $14.0 \mathrm{GHz}$

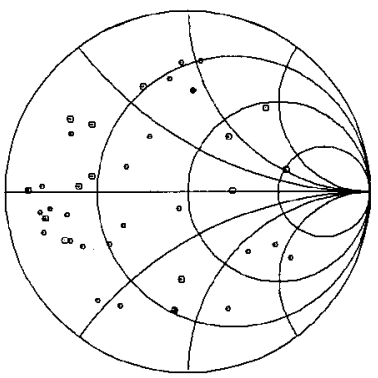

Measured 26.2 GHz

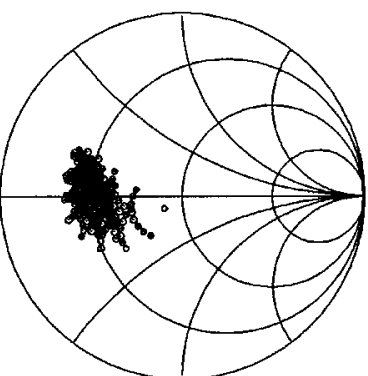

Simulated $4.1 \mathrm{GHz}$

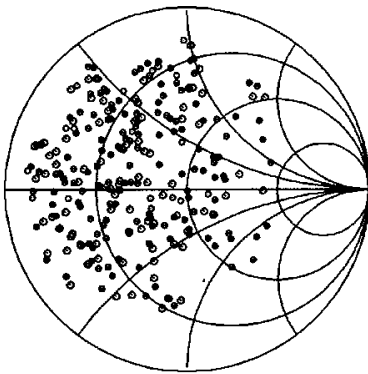

Simulated $14.0 \mathrm{GHz}$

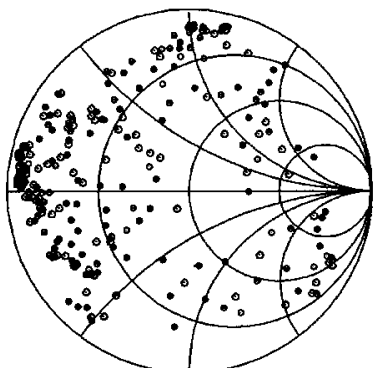

Simulated $26.2 \mathrm{GHz}$

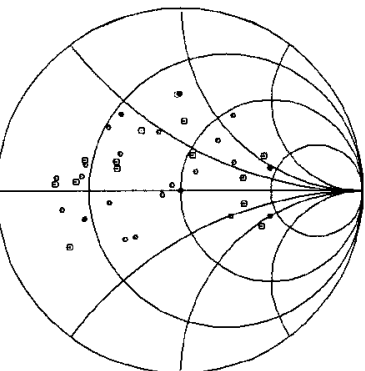

Measured $10 \mathrm{GHz}$

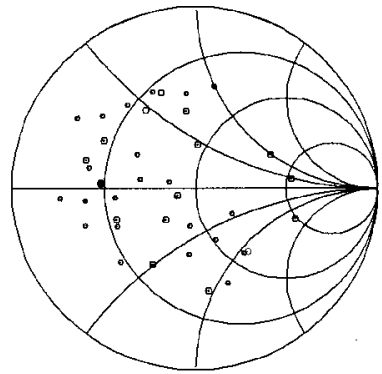

Measured $17.8 \mathrm{GHz}$

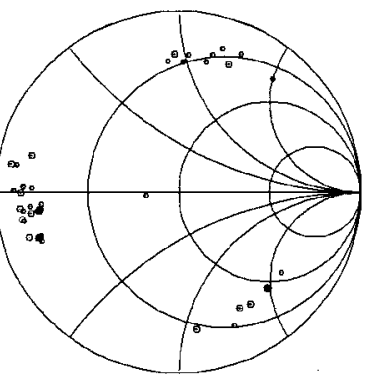

Measured $30.2 \mathrm{GHz}$

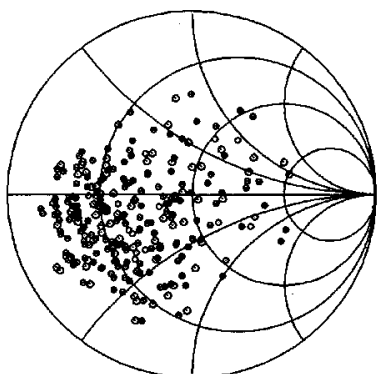

Simulated $10 \mathrm{GHz}$

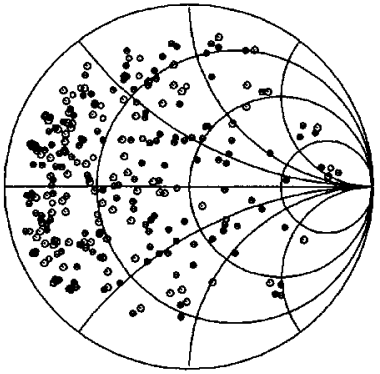

Simulated $17.8 \mathrm{GHz}$

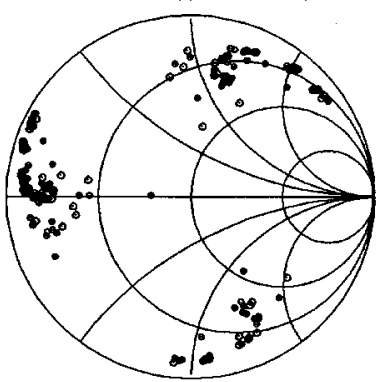

Simulated $30.2 \mathrm{GHz}$

Figure 5. Measured (35) and simulated (256) impedances of the 8-element reconfigurable MEMS matching network. The single-cell values are given in Table I.

at 4-30 GHz for a $50 \Omega$ load. The measurements were done on 35 switch settings out of 256 possible combinations, and the results match the simulated results very well. Notice that at $4-8 \mathrm{GHz}$, the electrical length of the loaded t-line is quite short and the mapped input impedance lies in the low-impedance region of the Smith chart. However, above $8 \mathrm{GHz}$, the loaded-line is long enough to transform a $50 \Omega$ load into a wide coverage of the Smith chart. Still, the loaded-line design is better suited for low-impedance matching as is evident from a study of the impedance loci at 4-30 GHz (as compared with the coverage at the $20 \Omega$ and $200 \Omega$ areas).

\section{B. Discussion of Impedance Coverage}

Effect of the MEMS Bridge Height. The height of the MEMS bridge is usually the most sensitive part in the fabrication process since the value of the fixed MIM or MAM capacitor is achieved with accuracy.
Therefore, the impedance coverage of the 8-element matching network is simulated with a fixed MAM capacitor of $850 \mathrm{fF}$ and a varying up-state MEMS capacitance. It is clear that the impedance coverage of the 8-element network does not change significantly if the MEMS up-state capacitance (and capacitance ratio) is changed from $34 \mathrm{fF}$ to $170 \mathrm{fF}$ (Fig. 6).

Effect of Loading Capacitance. The total down-state capacitance controls the lowest input impedance that can be achieved with a $50 \Omega$ load. Figure 7(a) presents the simulations with $\mathrm{CD}=200 \mathrm{fF}\left(C_{D-M E M S}=750\right.$ $\left.\mathrm{fF}, C_{M A M}=275 \mathrm{fF}\right), C_{D}=400 \mathrm{fF}\left(C_{D-M E M S}=750\right.$ $\left.\mathrm{fF}, C_{M A M}=850 \mathrm{fF}\right)$ and $C_{D}=900 \mathrm{fF}\left(C_{D-M E M S}=\right.$ $\left.1300 \mathrm{fF}, C_{M A M}=2900 \mathrm{fF}\right)$. The other switch and line parameters are the same as Table 1 . For $C_{D}=900 \mathrm{fF}$ and $s=480 \mu \mathrm{m}$, the minimum input impedance is plotted up to $20 \mathrm{GHz}$ due to Bragg frequency limitations, since above this frequency, the circuit results in very poor coverage of the Smith chart. On the other 


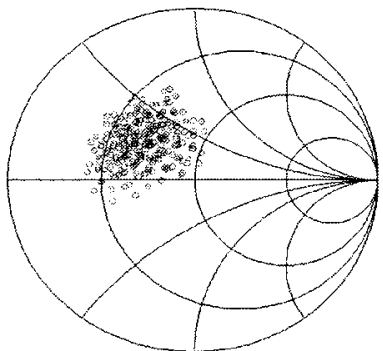

$6 \mathrm{GHz}$

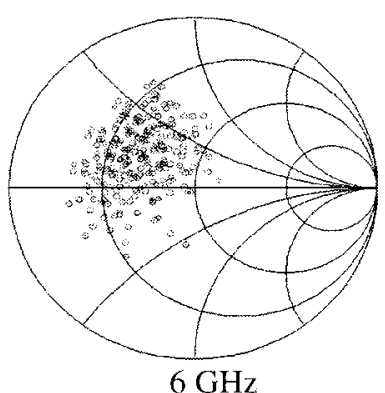

$6 \mathrm{GHz}$

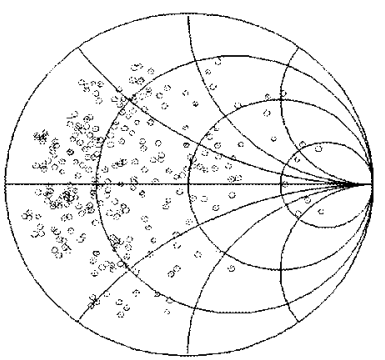

$12 \mathrm{GHz}$

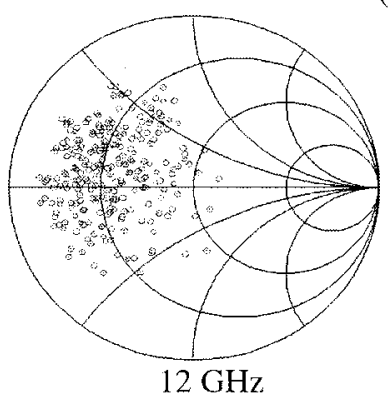

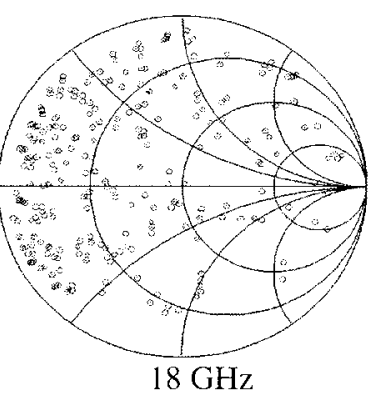

(a)

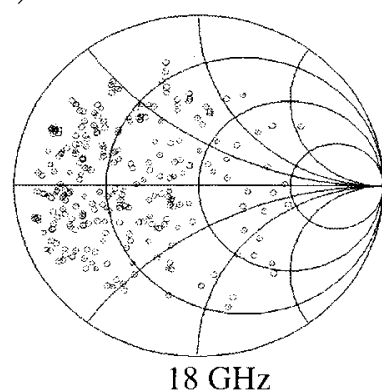

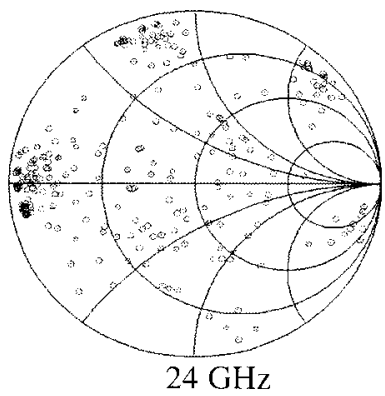

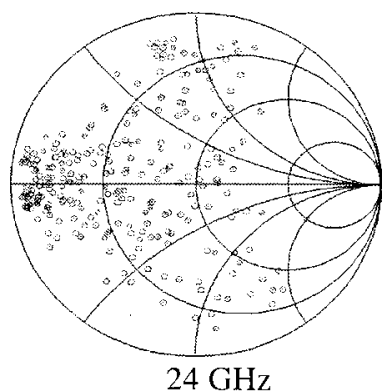

(b)

Figure 6. Simulated impedance coverage for the 8-element reconfigurable matching network with loading-capacitance ratios of (a) 2.8:1 $\left(C_{U-M E M S}=171 \mathrm{fF}, C_{D-M E M S}=750 \mathrm{fF}, C_{M A M}=850 \mathrm{fF}\right)$ and (b) 12.2:1 $\left(C_{U-M E M S}=34 \mathrm{fF} C_{D-M E M S}=750 \mathrm{fF}, C_{M A M}=850 \mathrm{fF}\right)$.

hand, for $C_{D}=200 \mathrm{fF}$ and $s=480 \mu \mathrm{m}$, the circuit results in excellent coverage of the Smith chart up to $36 \mathrm{GHz}$, but at the expense of a higher input impedance at $6-12 \mathrm{GHz}$. It is clear that for $6-24 \mathrm{GHz}$ applications, a down-state capacitance of 400-600 fF for $s=480 \mu \mathrm{m}$ is the best choice for low impedance matching and good Smith chart coverage.

Effect of Switched-Capacitor Separation. Figure 7(b) presents the effect of the period $s$ between the switched capacitors for $C_{D}=400 \mathrm{fF}$. Again, for $s=$ $900 \mu \mathrm{m}$, the results are plotted to $20 \mathrm{GHz}$ due to Bragg frequency limitations (the circuit is electrically large), and for $s=225 \mu \mathrm{m}$, one can extend the operation of the circuit up to $40 \mathrm{GHz}$. It is seen that the separation does not affect the minimum achievable input impedance at $6-24 \mathrm{GHz}$, but a closer look at the Smith chart indicates that the best coverage occurs for $s=300-600 \mu \mathrm{m}$ with $C_{D}=400 \mathrm{fF}$ in the $6-24-\mathrm{GHz}$ frequency range.

In general, many solutions in the $s$ and $C_{D}$ plane will lead to acceptable results in any frequency band.

\section{LOSS ANALYSIS AND CASE STUDIES}

The reconfigurable circuit results in a very high reflection coefficient for many different switch combi- nations; therefore, $S_{21}$ is not the correct measure of the circuit loss. The loss of any mismatched circuit is defined as:

$$
\text { Loss }=1-\left|S_{11}\right|^{2}-\left|S_{21}\right|^{2}
$$

and takes into account the loss in the CPW line, MEMS bridges, and MAM capacitors, and the radiation loss. The loss for different switch combinations can be easily obtained from the $S$-parameter measurements and from the circuit model of Figure 2(a) and Table 1, as shown in Figure 8). The peaks in the loss analysis are due to the low-impedance t-line section, which is synthesized in the reconfigurable circuit $\left(Z_{D}\right.$ $=23 \Omega, \varepsilon_{\text {reff } \_D}=38.2, N^{*} s=N^{*} 480 \mu \mathrm{m}$ ) when one or several switched capacitors are actuated. This low impedance section is bound by $45 \Omega \mathrm{t}$-line sections on either side, and will resonate when its effective length is $n \lambda_{g} / 2$ (half-wave resonator), where $\lambda_{g}$ is the guided wavelength in the resonator. For 2, 4, or 8 cascaded switched capacitors, the first resonant frequencies occur at 25.3, 12.6, and 6.3 GHz, respectively (Fig. 8), and is independent of the location of the switched capacitors. The simulated loss using the circuit model agrees very well with the values obtained from the measured $S$-parameters (Fig. 8). This allows us to use the circuit model for accurate loss analysis with non$50 \Omega$ loads. 


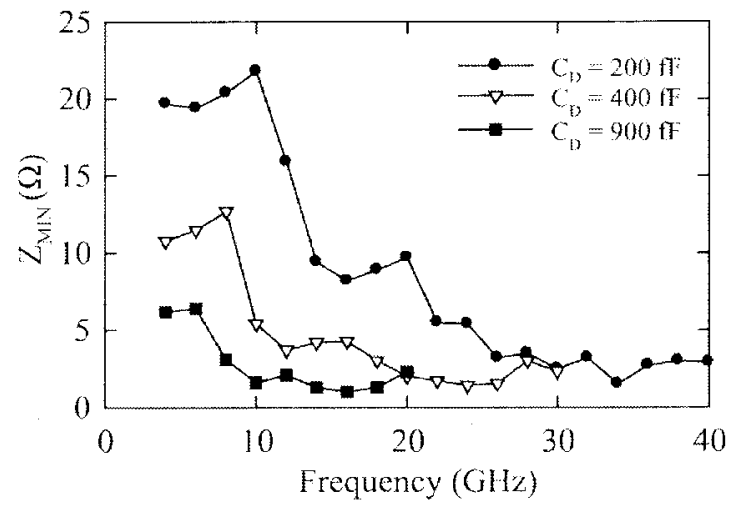

(a)

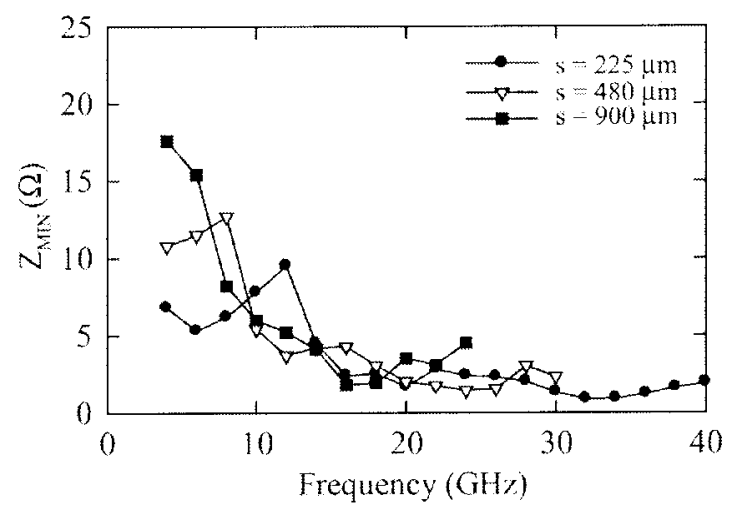

(b)

Figure 7. Simulated minimum input impedance for the 8-element matching network with a $50 \Omega$ load: (a) with different down-state capacitances and $\mathrm{s}=480 \mu \mathrm{m}$; (b) with different separation distances and $C_{D}=400 \mathrm{fF}$.

\section{A. Case Study: $10 \Omega$ and $20 \Omega$ Loads}

The reconfigurable loaded-line network was terminated with $10 \Omega$ and $20 \Omega$ loads and matched to $50 \Omega$ at 6, 12, 18, and $24 \mathrm{GHz}$ (see Figs. 9 and 10). It is evident that several switch combinations result in a good match at each frequency (Tables 2 and 3). Note that as the frequency increases, the circuit becomes electrically larger and results in a narrower bandwidth (a percentage of the center frequency). The loss increases significantly above $12 \mathrm{GHz}$, and becomes -2 $\mathrm{dB}(20 \Omega$ case $)$ and $-3 \mathrm{~dB}(10 \Omega$ case $)$ at $24 \mathrm{GHz}$. The reason is that the circuit is electrically lossy, since the down-state capacitor $Q$ is only 28 and the t-line loss is $0.56 \mathrm{~dB} / \mathrm{cm}$ at $24 \mathrm{GHz}$. If operation at $18-24 \mathrm{GHz}$ is needed, then one should employ a much smaller down-state capacitor and a smaller separation $s$, thus resulting in a more compact circuit. However, if wideband operation is needed $(6-24 \mathrm{GHz})$, then it would be best to use a quartz substrate (instead of a glass substrate) with a lower t-line loss. Also, the use of thicker gold plating for the bridges and MAM capac- itors can decrease the switched capacitor resistance to $0.3 \Omega$ (instead of the current value of $0.6 \Omega$ ). The loss of the reconfigurable circuit with a $10 \Omega$ load is presented in Table 4 for different t-line loss and device resistance values.

The input-reflection coefficient and loss can also be obtained from the measured $S$-parameters under different switch combinations (Fig. 11). It is seen that the experimental data agrees quite well with the circuit model of Figure 10, and again shows that the network is excellent up to $18 \mathrm{GHz}$. The network results in high matching loss for the $10 \Omega$ case at 24 $\mathrm{GHz}$, but this can be solved as discussed above.

\section{Case Study: $200 \Omega$ Load}

The 8-element reconfigurable matching network was primary designed to match low output-impedance amplifiers to $50 \Omega$. However, the circuit can also be used to match high-impedance components at $10-28 \mathrm{GHz}$ (Fig. 12). The simulated input impedances at the input of the 8-element matching network with a $200 \Omega$ load are shown in Figure 12. A detailed analysis indicates that the bandwidth and loss (which are not presented here) are comparable to the $10 \Omega$ case.

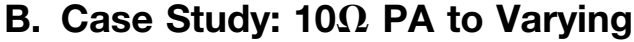

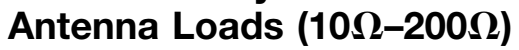

An interesting case for power amplifiers is when the load impedance (such as the antenna) varies over a wide impedance range. The matching network still needs to be used when connecting a $10 \Omega$ PA to a $10 \Omega$

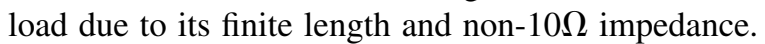
The reconfigurable network is versatile enough that it can easily render such a match possible with several switch combinations, under virtually any load condition (Table 5, Figs. 13 and 14) but at the expense of

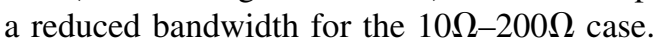

The above case studies prove that the loaded-line reconfigurable network is an extremely versatile design, and is capable of a wide range of impedance matching (even a 20:1 case) over a large frequency band without any excessive loss. Although we have used solely real impedances, the reconfigurable matching network has virtually the same performance for complex loads on the same VSWR circles, and this will not be repeated here for conciseness.

\section{INTERMODULATION MEASUREMENTS}

The intermodulation analysis of MEMS switches, varactors, and tunable filters is presented in [11] and will 

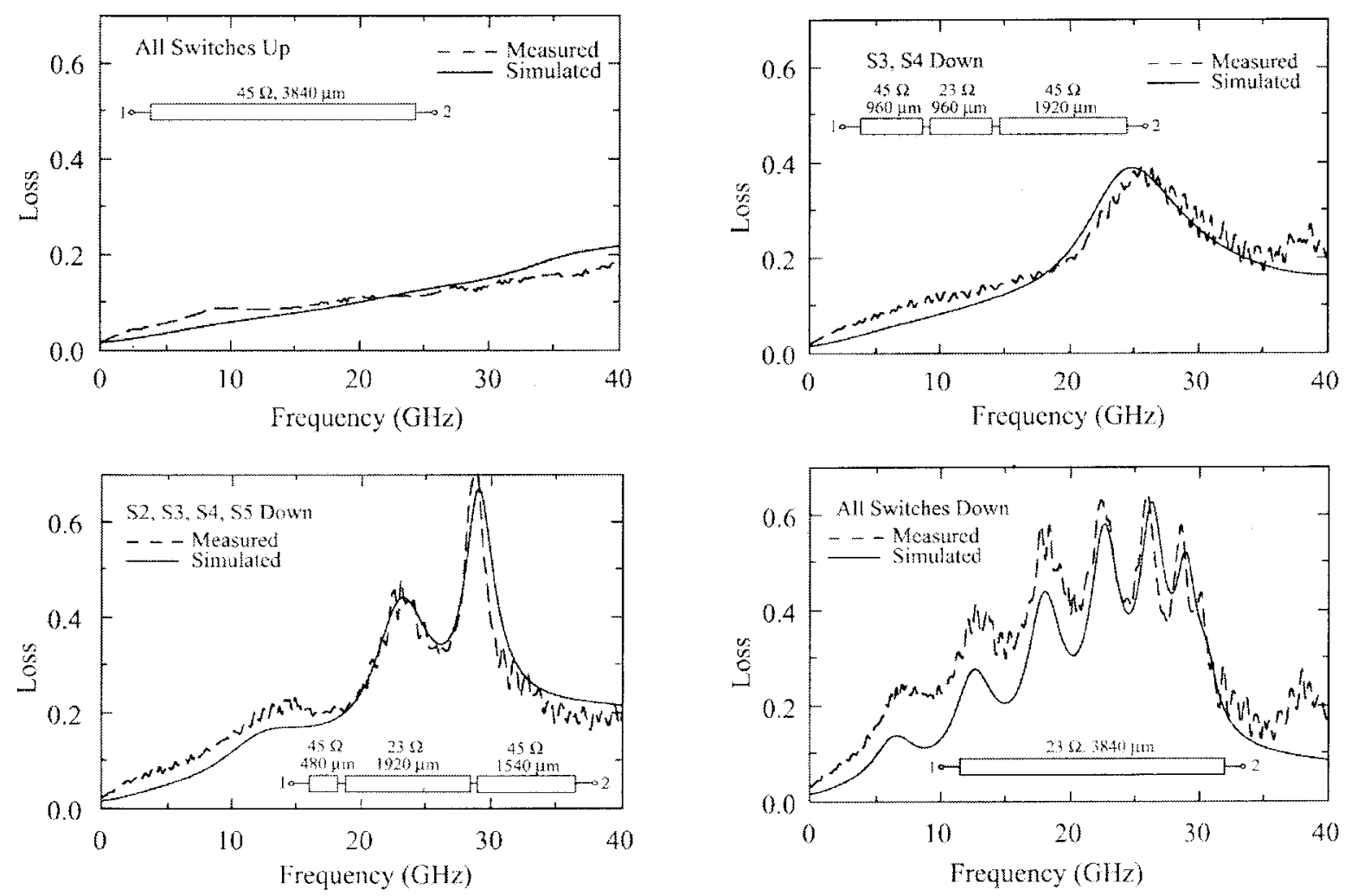

Figure 8. Loss of the 8-element matching network obtained from measured $S$-parameters and from the circuit model for different switch combinations.
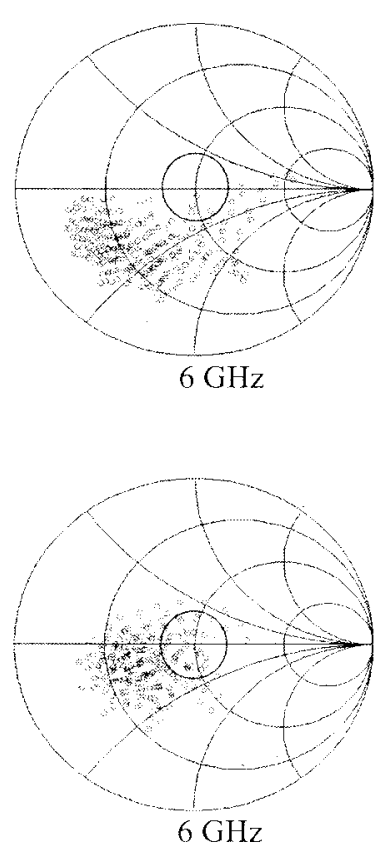

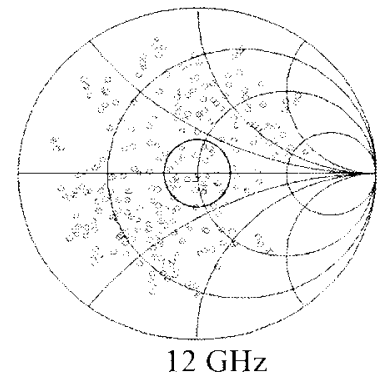

(a)

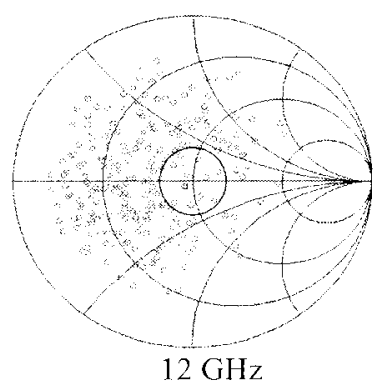

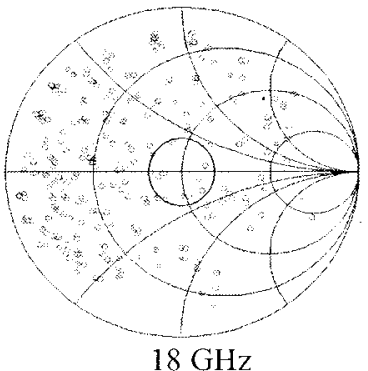

$18 \mathrm{GHz}$

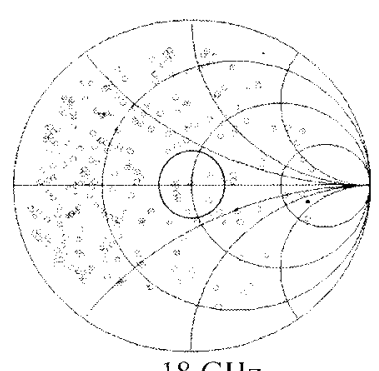

$18 \mathrm{GHz}$
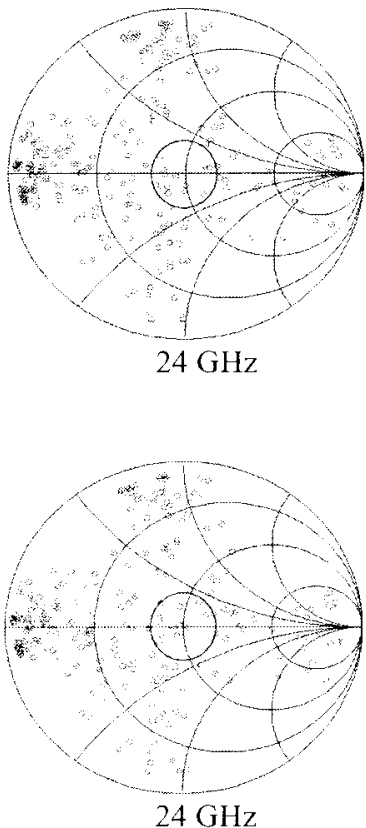

$24 \mathrm{GHz}$

(b)

Figure 9. Simulated impedances seen at the input of the 8-element matching network with (a) $10 \Omega$ and (b) $20 \Omega$ load (Smith chart is based on $50 \Omega$ ). The circle shows the -15 -dB matching area. 

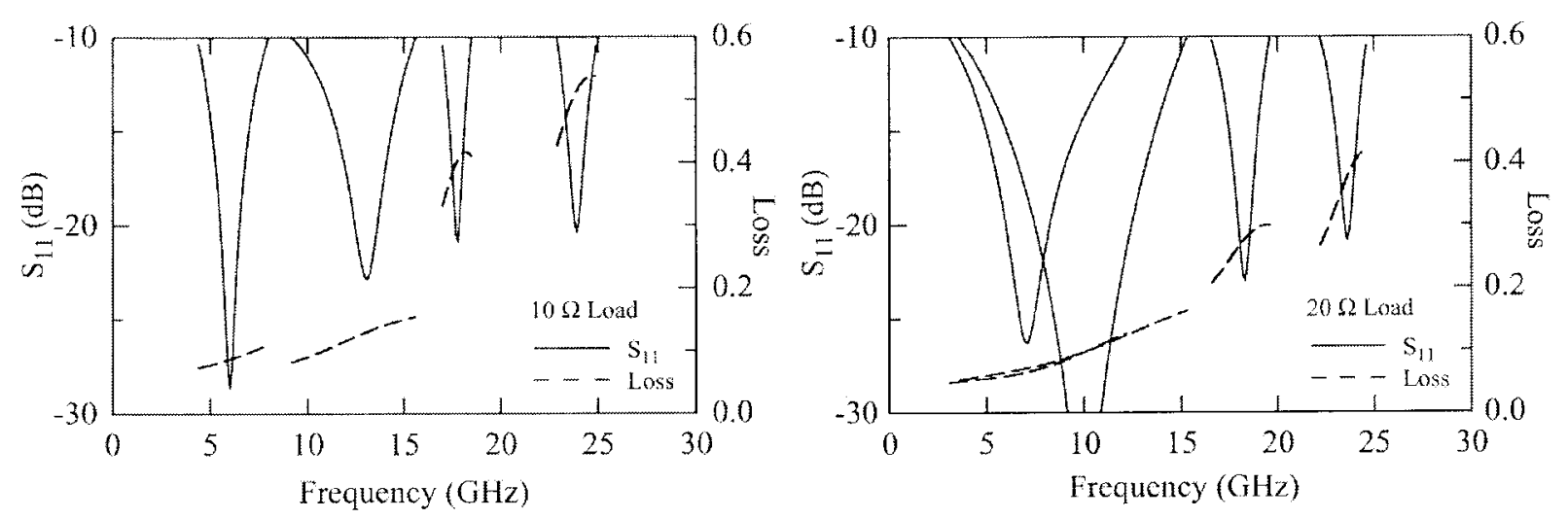

Figure 10. Simulated input reflection coefficient and loss of the 8-element matching network at 6 , 12,18 , and $24 \mathrm{GHz}$ with (a) $10 \Omega$ and (b) $20 \Omega$ loads matched to $50 \Omega$. The specific switch combinations are presented in Tables II and III in italics.

not be repeated here. The findings in [11] are that MEMS circuits generate insignificant amount of intermodulation products, especially if the difference $\Delta f$ is higher than the mechanical resonant frequency of the bridge $(90-100 \mathrm{kHz})$. Intermodulation measurements of the 8-element matching network were done at 8 and $17 \mathrm{GHz}$ (Fig. 14), and the $8-\mathrm{GHz}$ results are shown due to the higher dynamic range. The circuit was terminated with a $50 \Omega$ load or with a short circuit. In the case of a short-circuit condition, the intermodulation signal was measured at the input port using a circulator. It is seen that the intermodulation products are truly negligible (IIP3 $>+30 \mathrm{dBm}$ ), even

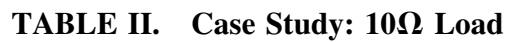

\begin{tabular}{|c|c|c|}
\hline Switch Combination & $\begin{array}{c}S_{11} \text { at } \\
\text { Center Freq. } \\
(\mathrm{dB}) \text { and } \\
-10-\mathrm{dB} \\
\text { BW }(\mathrm{GHz})\end{array}$ & $\begin{array}{c}\text { Loss at } \\
\text { Center Freq. } \\
\text { and Max. } \\
\text { Loss in } \\
-10-\mathrm{dB} \\
\text { Band }\end{array}$ \\
\hline \multicolumn{3}{|l|}{$6 \mathrm{GHz}$} \\
\hline S5, S6, S7 & $-20.6(3.1)$ & $0.09(0.10)$ \\
\hline S5, S6, S7, S8 & $-28.6(3.6)$ & $0.09(0.11)$ \\
\hline $\mathrm{S} 4, \mathrm{~S} 6, \mathrm{~S} 7, \mathrm{~S} 8$ & $-17.4(3.2)$ & $0.09(0.10)$ \\
\hline \multicolumn{3}{|l|}{$12 \mathrm{GHz}$} \\
\hline S7, S8 & $-17.1(6.4)$ & $0.12(0.16)$ \\
\hline S3, S6, S7 & $-44.5(2.1)$ & $0.21(0.23)$ \\
\hline $\mathrm{S} 1, \mathrm{~S} 4, \mathrm{~S} 7, \mathrm{~S} 8$ & $-23.9(2.5)$ & $0.19(0.20)$ \\
\hline \multicolumn{3}{|l|}{$18 \mathrm{GHz}$} \\
\hline $\mathrm{S} 2, \mathrm{~S} 4, \mathrm{~S} 7$ & $-20.0(1.3)$ & $0.44(0.47)$ \\
\hline $\mathrm{S} 2, \mathrm{~S} 3, \mathrm{~S} 4, \mathrm{~S} 7$ & $-16.5(1.6)$ & $0.47(0.49)$ \\
\hline S2, S4, S6, S7, S8 & $-17.6(1.5)$ & $0.41(0.42)$ \\
\hline \multicolumn{3}{|l|}{$24 \mathrm{GHz}$} \\
\hline S6, S7 & $-19.9(2.0)$ & $0.52(0.54)$ \\
\hline $\mathrm{S} 1, \mathrm{~S} 2, \mathrm{~S} 4$ & $-17.9(2.3)$ & $0.52(0.56)$ \\
\hline $\mathrm{S} 3, \mathrm{~S} 4, \mathrm{~S} 6, \mathrm{~S} 7, \mathrm{~S} 8$ & $-25.1(3.5)$ & $0.58(0.65)$ \\
\hline
\end{tabular}

under short-circuit conditions (Fig. 15). The IIP3 increases with $\Delta f^{4}$ and, therefore, it is expected to be $>$ $+70 \mathrm{dBm}$ for a $\Delta f$ of $1 \mathrm{MHz}$. This is so low that it is simply unmeasurable in most experimental setups. These findings confirm the results of [11].

\section{POWER ANALYSIS AND MEASUREMENTS}

The position of a MEMS switch changes if a DC or RF voltage is applied between the bridge electrodes, since the electrostatic force is dependent on $V^{2}$, and

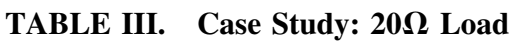

\begin{tabular}{|c|c|c|}
\hline Switch Combination & $\begin{array}{c}S_{11} \text { at } \\
\text { Center Freq. } \\
(\mathrm{dB}) \text { and } \\
-10-\mathrm{dB} \mathrm{BW} \\
(\mathrm{GHz})\end{array}$ & $\begin{array}{l}\text { Loss at } \\
\text { Center Freq. } \\
\text { and Max. } \\
\text { Loss in } \\
-10-\mathrm{dB} \\
\text { Band }\end{array}$ \\
\hline \multicolumn{3}{|l|}{$6 \mathrm{GHz}$} \\
\hline S6 & $-20.0(9.1)$ & $0.06(0.13)$ \\
\hline S5 & $-23.6(5.8)$ & $0.06(0.08)$ \\
\hline S5, S7 & $-21.8(8.8)$ & $0.07(0.12)$ \\
\hline \multicolumn{3}{|l|}{$12 \mathrm{GHz}$} \\
\hline S7 & $-20.1(11)$ & $0.10(0.12)$ \\
\hline S6, S8 & $-22.3(11.7)$ & $0.12(0.16)$ \\
\hline $\mathrm{S} 2, \mathrm{~S} 4, \mathrm{~S} 5, \mathrm{~S} 7$ & $-25.8(3.5)$ & $0.18(0.19)$ \\
\hline \multicolumn{3}{|l|}{$18 \mathrm{GHz}$} \\
\hline S4, S6, S8 & $-18.14(4.7)$ & $0.29(0.34)$ \\
\hline S5, S6, S7 & $-20.5(3.0)$ & $0.27(0.30)$ \\
\hline S3, S4, S5, S7, S8 & $-20.5(3.5)$ & $0.34(0.36)$ \\
\hline \multicolumn{3}{|l|}{$24 \mathrm{GHz}$} \\
\hline $\mathrm{S} 2, \mathrm{~S} 3$ & $-17(2.4)$ & $0.36(0.42)$ \\
\hline S6, S7 & $-17.5(2.6)$ & $0.40(0.42)$ \\
\hline $\mathrm{S} 4, \mathrm{~S} 5, \mathrm{~S} 7, \mathrm{~S} 8$ & $-17.7(2.6)$ & $0.52(0.61)$ \\
\hline
\end{tabular}


TABLE IV. Simulated Loss of the Reconfigurable 8-Element Circuit with a $10 \Omega$ Load and Different T-Line Loss and Switched Capacitor Resistance

\begin{tabular}{lccccc}
\hline $\begin{array}{l}\alpha \text { at } 10 / 20 \\
\mathrm{GHz}(\mathrm{dB} / \mathrm{cm})\end{array}$ & $\begin{array}{c}R_{\text {MEMS }}+R_{\text {MAM }} \\
(\Omega)\end{array}$ & $\begin{array}{c}\text { Loss, 6 GHz } \\
\text { S5, S6, S7, S8 }\end{array}$ & $\begin{array}{c}\text { Loss, 12 GHz } \\
\text { S7, S8 }\end{array}$ & $\begin{array}{c}\text { Loss, 18 GHz S2, } \\
\text { S4, S6, S7, S8 }\end{array}$ & $\begin{array}{c}\text { Loss, 24 GHz } \\
\text { S6, S7 }\end{array}$ \\
\hline $0.35 / 0.52$ & 0.6 & $0.09(0.11)$ & $0.12(0.16)$ & $0.41(0.42)$ & $0.52(0.54)$ \\
$0.35 / 0.52$ & 0.3 & $0.08(0.10)$ & $0.10(0.12)$ & $0.32(0.32)$ & $0.41(0.42)$ \\
$0.18 / 0.27$ & 0.6 & $0.07(0.09)$ & $0.10(0.13)$ & $0.37(0.38)$ & $0.48(0.50)$ \\
$0.18 / 0.27$ & 0.3 & $0.06(0.08)$ & $0.08(0.10)$ & $0.27(0.27)$ & $0.35(0.36)$ \\
\hline
\end{tabular}

TABLE V. Case Study: $10 \Omega$ Source and $10 \Omega$ or $200 \Omega$ Load

\begin{tabular}{|c|c|c|c|c|c|c|}
\hline Frequency & Switch Combination & $\begin{array}{c}S_{11} \text { at } \\
\text { Center Freq. } \\
(\mathrm{dB}) \text { and } \\
-10-\mathrm{dB} \mathrm{BW} \\
(\mathrm{GHz})\end{array}$ & $\begin{array}{c}\text { Loss at } \\
\text { Center Freq. } \\
\text { and Max. } \\
\text { Loss in } \\
-10-\mathrm{dB} \\
\text { Band }\end{array}$ & $\begin{array}{c}\text { Switch } \\
\text { Combination }\end{array}$ & $\begin{array}{c}S_{11} \text { at } \\
\text { Center Freq. } \\
(\mathrm{dB}) \text { and } \\
-10-\mathrm{dB} \mathrm{BW} \\
(\mathrm{GHz})\end{array}$ & $\begin{array}{l}\text { Loss at } \\
\text { Center Freq. } \\
\text { and Max. } \\
\text { Loss in } \\
-10-\mathrm{dB} \\
\text { Band }\end{array}$ \\
\hline & $10 \Omega$ to $10 \Omega$ & & & $200 \Omega$ to $10 \Omega$ & & \\
\hline $6 \mathrm{GHz}$ & $\mathrm{S} 2, \mathrm{~S} 3, \mathrm{~S} 4, \mathrm{~S} 5, \mathrm{~S} 6, \mathrm{~S} 7$ & $-18.3,(1.3)$ & $0.13(0.14)$ & & $-18.7,(1.2)$ & $0.09(0.10)$ \\
\hline $12 \mathrm{GHz}$ & $\mathrm{S} 1, \mathrm{~S} 2, \mathrm{~S} 7, \mathrm{~S} 8$ & $-48.3,(5.0)$ & $0.17(0.23)$ & S4, S8 & $-31.8,(0.6)$ & $0.42(0.42)$ \\
\hline $18 \mathrm{GHz}$ & $\mathrm{S} 1, \mathrm{~S} 2$ & $-22.6,(1.3)$ & $0.42(0.43)$ & $\mathrm{S} 1, \mathrm{~S} 2, \mathrm{~S} 3, \mathrm{~S} 4, \mathrm{~S} 5$ & $-28.1,(1.7)$ & $0.37(0.37)$ \\
\hline $24 \mathrm{GHz}$ & $\mathrm{S} 1, \mathrm{~S} 2, \mathrm{~S} 7, \mathrm{~S} 8$ & $-19.1,(2.5)$ & $0.45(0.47)$ & $\mathrm{S} 1, \mathrm{~S} 2$ & $-28.3,(1.8)$ & $0.37(0.38)$ \\
\hline
\end{tabular}

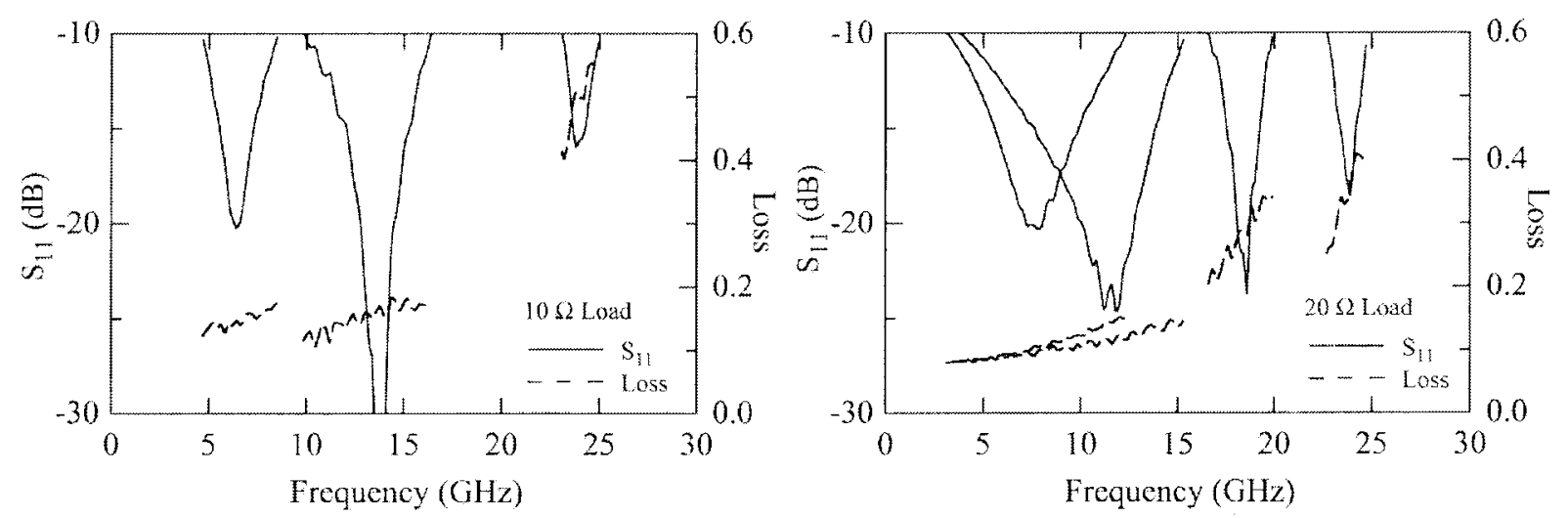

Figure 11. Input-reflection coefficient and loss obtained from the measured $S$-parameters of the 8 -element matching network with $10 \Omega$ and $20 \Omega$ loads. The $10 \Omega$ load is matched to $50 \Omega$ at $6 \mathrm{GHz}$ using (S5, S6, S7, S8), at $12 \mathrm{GHz}$ (S7, S8), and at $24 \mathrm{GHz}$ (S6, S7). The $20 \Omega$ load is matched to $50 \Omega$ at $6 \mathrm{GHz}$ using (S6), at $12 \mathrm{GHz}(\mathrm{S} 7)$, at $18 \mathrm{Ghz}(\mathrm{S} 5, \mathrm{~S} 6, \mathrm{~S} 7)$ and at $24 \mathrm{Ghz}$ (S2, S3).

this translates to $V_{\mathrm{rms}}^{2}$ for RF voltages [10]. If $V_{r m s}$ is equal or greater than the pull-down voltage of the MEMS switch ( $V_{p}$ is typically $\left.15-30 \mathrm{~V}\right)$, the switch will self-actuate to the down-state position. Another problem related to high RF power is the hold-down voltage in the down-state position ( $V_{h}$ is typically 5-8 $\mathrm{V})$. This is important for switched capacitors, since the RF voltage across the MEMS switch can be quite high. The reason for this is that the switch is not connected to a ground, and therefore can sustain a high-RF voltage even in the down-state position.
Also, the RF current in the switch in the down-state position can be quite high, and this is especially true in standing-wave circuits. Still, switched-capacitor circuits result in more favorable down-state conditions than standard RF MEMS switches because the impedance to ground at any switch location is quite high $(X=-j 33 \Omega$ at $12 \mathrm{GHz})$, compared to a capacitive short-circuit (around $X=-j 5 \Omega$ at $12 \mathrm{GHz}$ ).

The rms voltages and currents $\left(V_{R F \text {-rms }}, I_{R F \text {-rms }}\right)$ for the $N$-switched capacitors under different combination can be easily obtained using a circuit simulator 

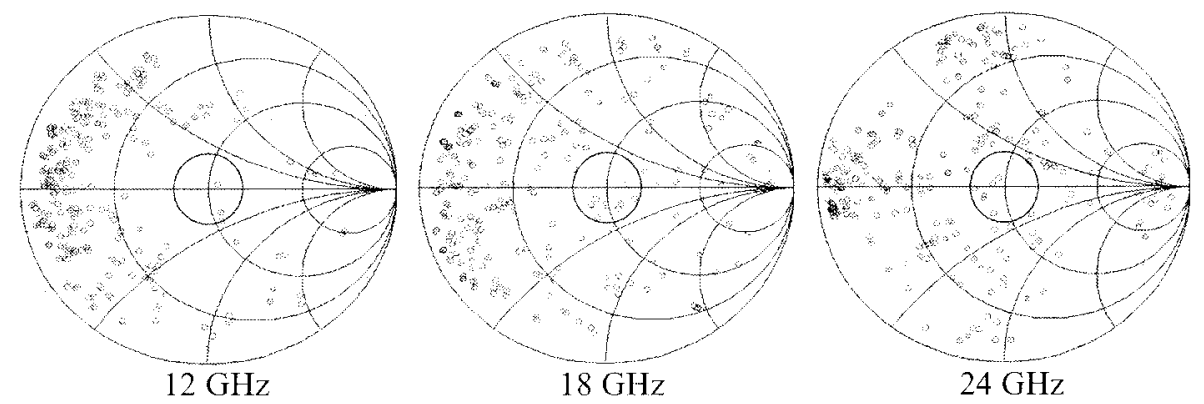

Figure 12. Simulated impedances seen by the $50 \Omega$ source connected to the 8 -element matching network and a $200 \Omega$ load.

and the circuit model of Table 1 (Agilent ADS). The 8 -element circuit was terminated with $10 \Omega$ or $20 \Omega$ loads and matched with the same switch combinations as in Tables 2 and 3 (Fig. 16). An input-RF power of $+27-\mathrm{dBm}(500 \mathrm{~mW})$ was used, but the voltages and current for different powers can be easily obtained, since they are proportional to $\sqrt{ }(\mathrm{P})$. From Figure 16, it is easy to locate which switches are in the down-sate position from the large simulated current in the switched-capacitors. The simulated voltage is divided between the MEMS switch $\left(C_{U-M E M S}=91 \mathrm{fF}, C_{D}\right.$ $M E M S=750 \mathrm{fF})$ and the MAM capacitor $\left(C_{M A M}=\right.$ $850 \mathrm{fF}$ ), and therefore, the voltage across the MEMS switch is $0.9 V_{R F-\text { rms }}$ and $0.47 V_{R F-\text {-rms }}$ for the up-state and down-state positions, respectively. The current in the MEMS switch is the same as the MAM capacitors (there are two MAM capacitors connected to each MEMS switch). The simulations indicate that the rms voltages across the MEMS switches for the $10 \Omega$ and $20 \Omega$ loads are below $6 \mathrm{~V}$ for the up-state and downstate positions at $6-18 \mathrm{GHz}$, and therefore, there is no failure due to self-actuation or hold-down. The rms current values are also reasonable (up to $300 \mathrm{~mA}$ at $6-18 \mathrm{GHz}$ ) which can be easily sustained by 0.8 $\mu \mathrm{m}$-thick gold bridges [12]. However, at $24 \mathrm{GHz}$, the down-state voltage and current in S6 and S7 are quite high, and will likely result in a hold-down condition (MEMS switch voltage $>6 \mathrm{~V}$ ) or a current-failure
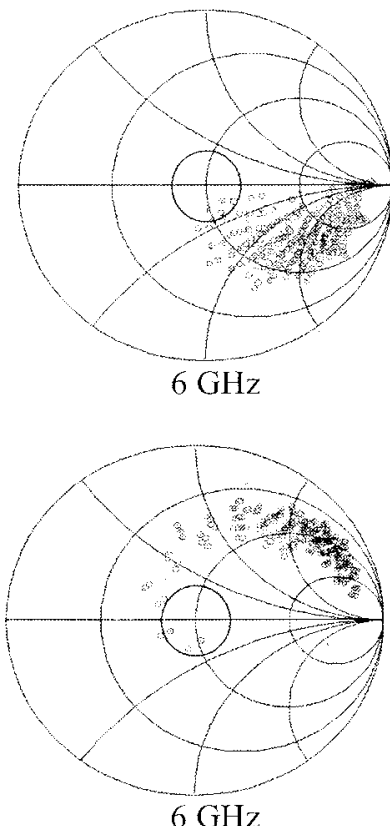

$6 \mathrm{GHz}$
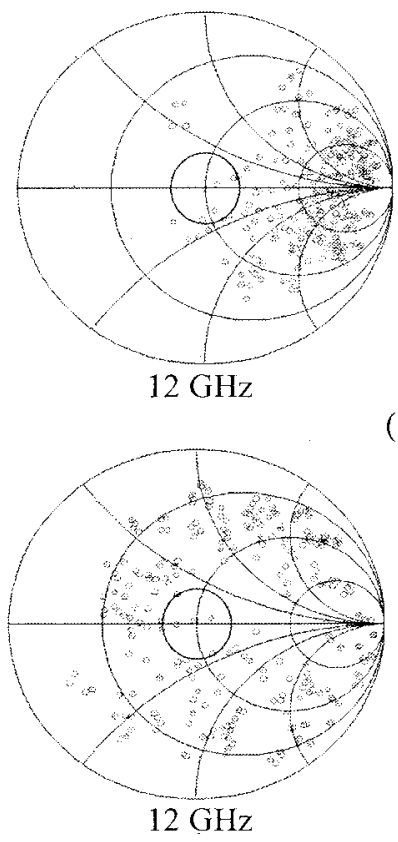

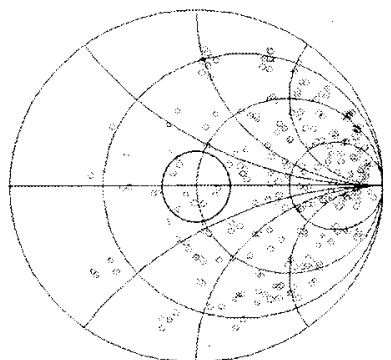

$18 \mathrm{GHz}$

(a)

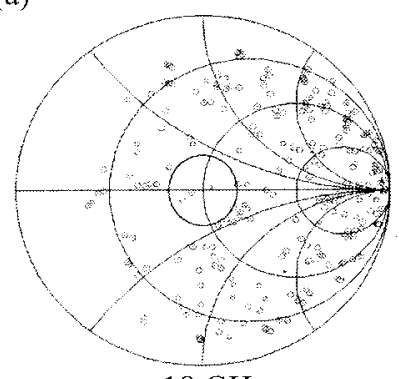

$18 \mathrm{GHz}$
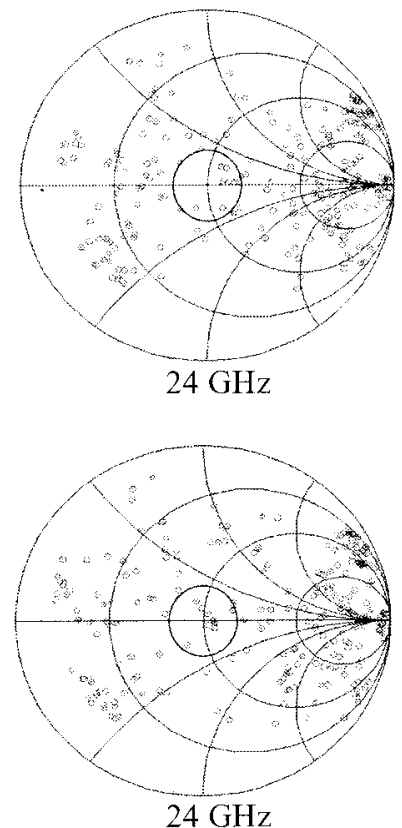

(b)

Figure 13. Simulated impedances seen by a PA $\left(Z_{P A}=10 \Omega\right)$ connected to the 8-element matching network and antenna with impedance $\left(Z_{A}\right)$ of (a) $10 \Omega$ or (b) $200 \Omega$. The Smith chart is a $10 \Omega$ chart in both cases above. 

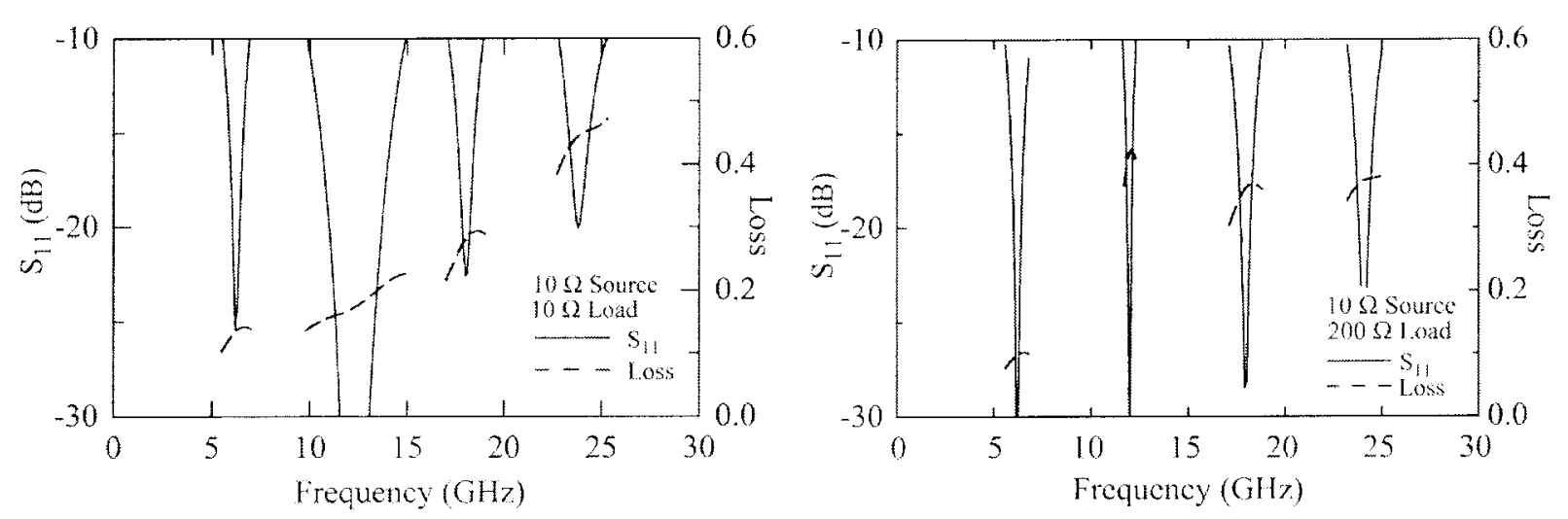

Figure 14. Simulated input-reflection coefficient and loss of a PA $\left(Z_{P A}=10 \Omega\right)$ connected to the 8 -element matching network and an antenna impedance $\left(Z_{A}\right)$ of $10 \Omega$ or $200 \Omega$.

condition $\left(I_{R F \text {-rms }}=400 \mathrm{~mA}\right)$. The high current level can be explained by the value of the loading reactance at $24 \mathrm{GHz}(X=-j 16 \Omega)$, which is approaching a short circuit, and the high-voltage levels are due to the electrically long low-impedance resonator, which is

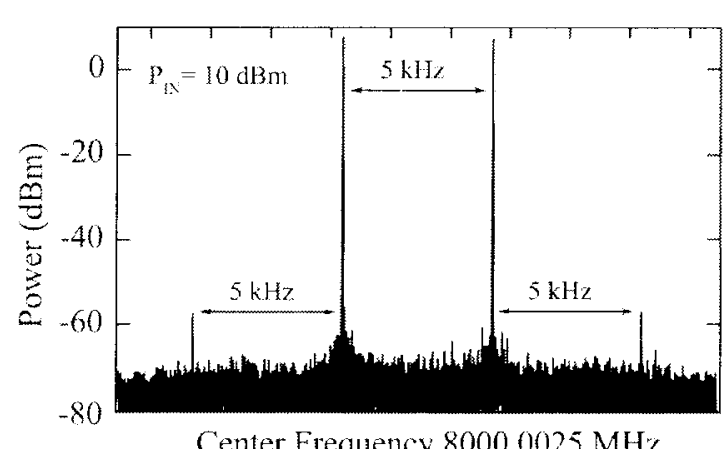

(a)

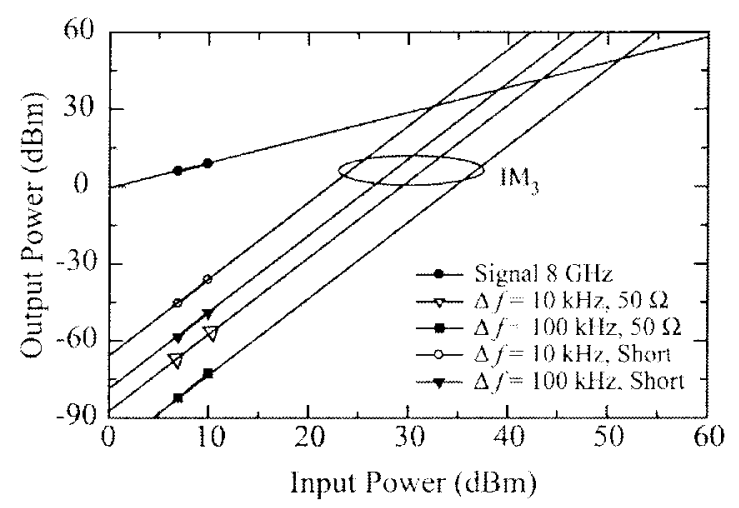

(b)

Figure 15. (a) Representative measured spectrum of the output $(50 \Omega)$ or input (short circuit) signals at $8 \mathrm{GHz}$ in the intermodulation setup; (b) measured third-order intermodulation as a function of $\Delta f$ and the input power level. synthesized even with the use of two switches in the down-state position. Again, for $-20-\mathrm{GHz}$ operation, it is best to use a smaller loading capacitance and a shorter separation s.

Power measurements using on-wafer $50 \Omega$ set-ups are not easily achievable, and if a lumped $10 \Omega$ load is placed at port 2, then $S_{21}$ cannot be measured, and, most important, the absorbed power in the lumped load cannot be measured unless a precise calorimetric technique is used. Another method is to use a fixed impedance transforming network and a $50 \Omega$ load (that is, power meter) at port 2, with the goal of presenting an effective load of $10 \Omega$ to the reconfigurable network; however, this is quite narrowband, and due to the electrical delay in the CPW probe launchers, one cannot be sure that the impedance seen at port 2 is actually as designed. We have therefore decided to load the reconfigurable network with a standard $50 \Omega$ load (that is, power meter and a CPW probe) and purposely mismatch the input port by selecting different switch combinations. The important value in Figure 17 is the achieved VSWR or $S_{11}$ under the different switch combinations, since this gives a good idea of the standing waves in the circuit.

The reconfigurable circuit was measured at 8 and 17.6 GHz due to the availability of TWT amplifiers at these frequencies. The measured maximum on-wafer power was $+29 \mathrm{dBm}$ at $8 \mathrm{GHz}$ and $+30.5 \mathrm{dBm}$ at $17.6 \mathrm{GHz}$ (Fig. 17). At $8 \mathrm{GHz}$, it is evident that the 8 -element circuit can handle up to $+29 \mathrm{dBm}$ of $\mathrm{RF}$ power (loading reactance is $X=-j 50 \Omega$ ) for different VSWR conditions. In this case, the minimum input impedance which can be achieved is about $13 \Omega$ (see Figs. 5 and 7), which corresponds to $S_{11}=-4.6 \mathrm{~dB}$. At $17.6 \mathrm{GHz}$, the circuit starts to self-actuate or holddown at an RF power of $+28-29 \mathrm{dBm}$ when $\mathrm{S} 4$ and $\mathrm{S} 7$ were actuated $\left(S_{11}=-2.6 \mathrm{~dB}\right)$. The case of $(\mathrm{S} 2$, 

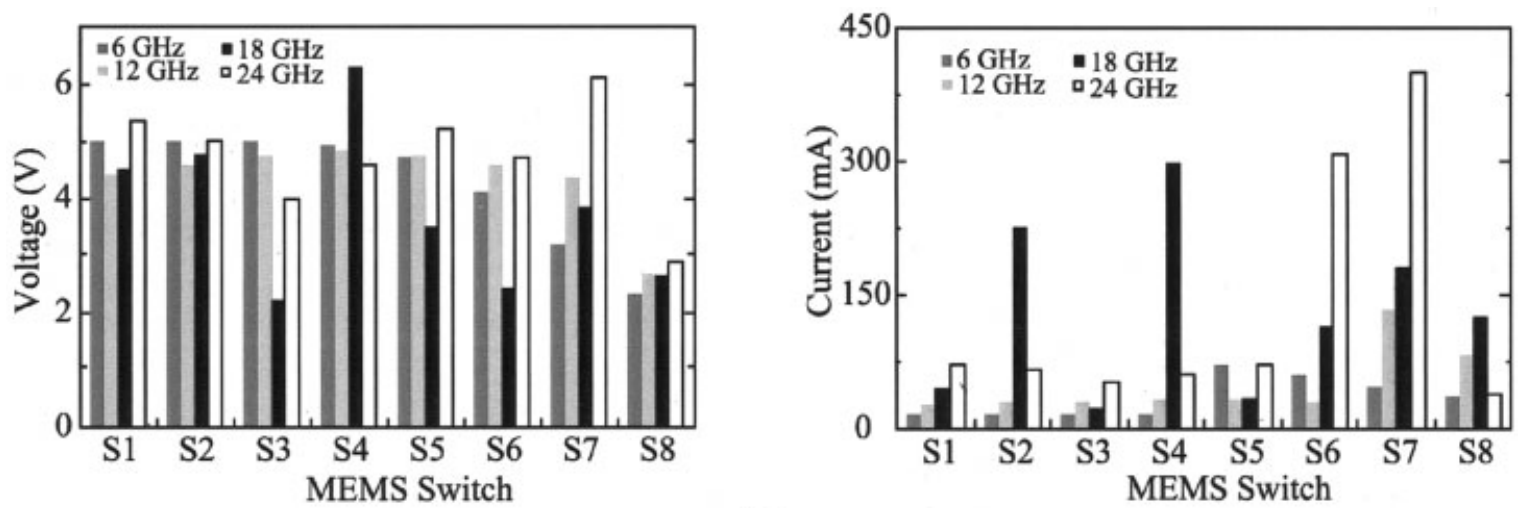

(a)
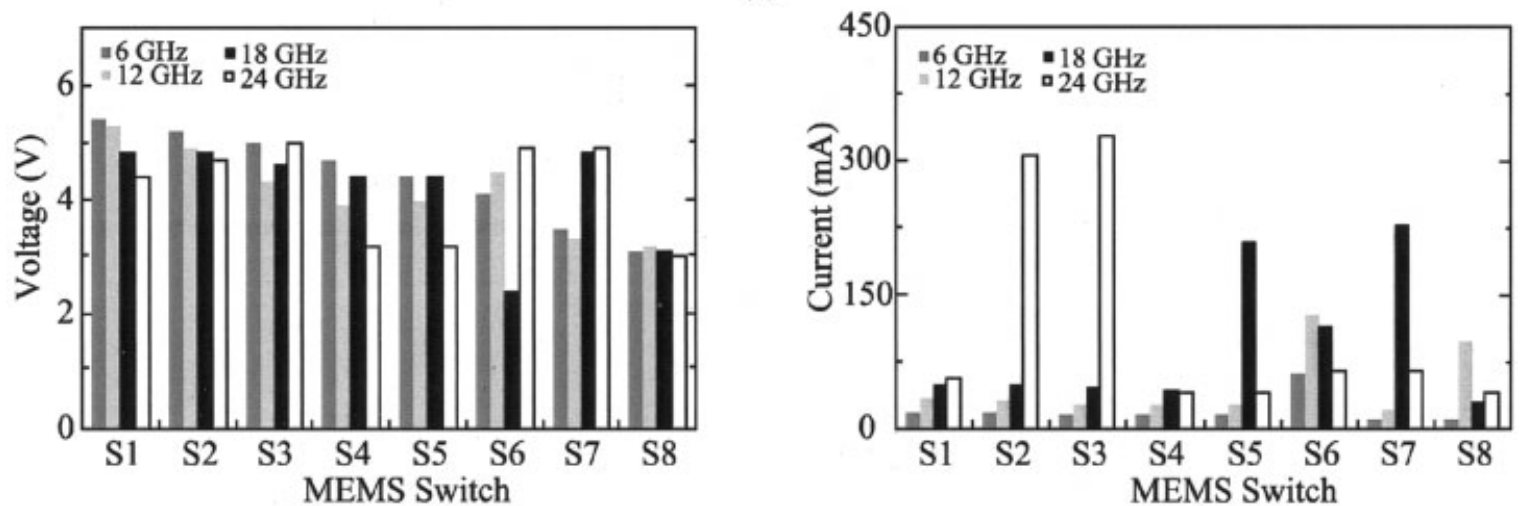

(b)

Figure 16. Simulated rms voltages and currents for the 8-element matching network with $+27-\mathrm{dBm}$ input power at $6,8,12$, and $24 \mathrm{GHz}$. The component was terminated with a load of (a) $10 \Omega$ or (b) $20 \Omega$, and matched to $50 \Omega$ (see Tables II and III, italic entries).

S7) with a VSWR of 13.7 is particularly interesting since one can see an RF self-actuation of several switches at $28.5 \mathrm{dBm}$ thereby changing the reconfigurable circuit impedance (Fig. 18). It is quite hard to determine exactly which switches are actuated as S3

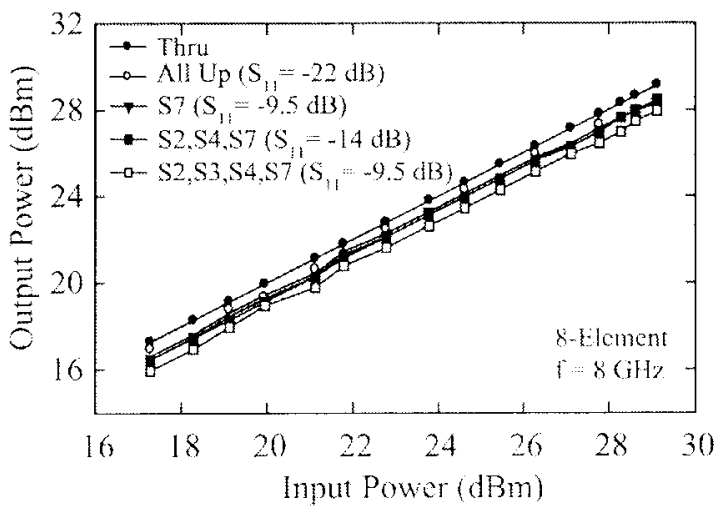

and S4 are starting to be pulled down, the impedance of the network changes and different voltage distribution occurs on the 8-element network. A coupledmicrowave-circuit mechanical analysis is needed to find the solution in a dynamic fashion and is not done

Figure 17. The measured power handling of the 8-element MEMS matching networks at 8 and 17.6 GHz under different VSWR $\left(S_{11}\right)$ conditions.

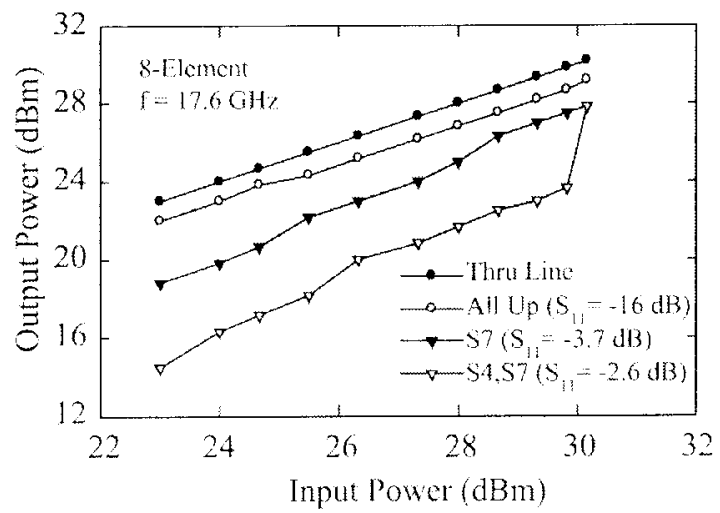




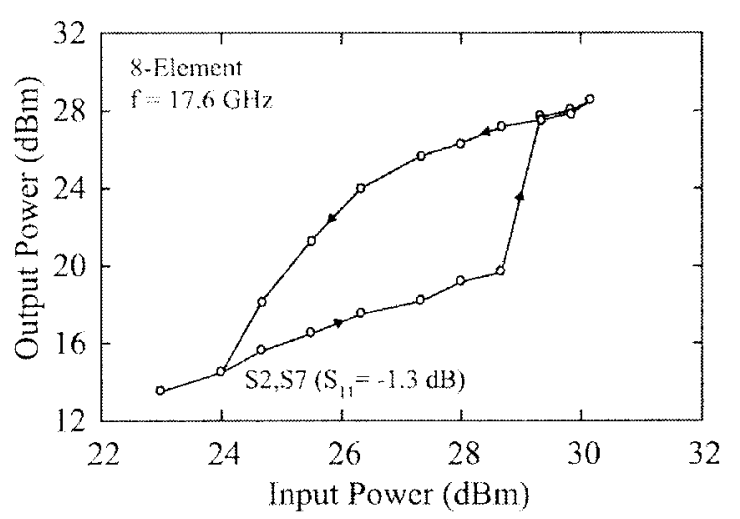

(a)

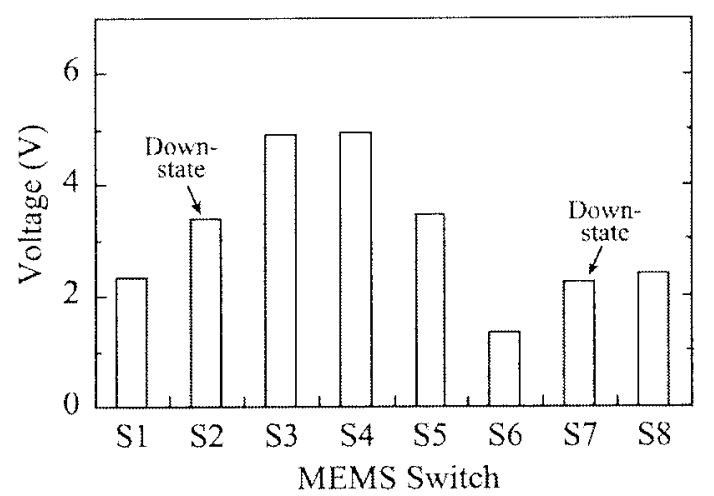

(b)

Figure 18. An RF self-actuation and hold-down case at 17.6 GHz: (a) measured output power and (b) simulations of the rms circuit voltages when $(\mathrm{S} 2, \mathrm{~S} 7)$ are actuated at $P_{I N}=$ $28.5 \mathrm{dBm}$.

in this work. An RF hold-down is present in this new circuit until the power is reduced to $24 \mathrm{dBm}$, where these particular switches are released to the up-state position and the circuit returns to its initial condition.

We feel confident that the 8-element reconfigurable network with $g_{0}=1.1 \mu \mathrm{m}, V_{p}=15-20 \mathrm{~V}$, and $V_{h}=6-8 \mathrm{~V}$, can handle $>1 \mathrm{~W}$ of RF power at 8 $\mathrm{GHz}$, and around $600 \mathrm{~mW}$ at $18 \mathrm{GHz}$ under different VSWR conditions. If higher-power handling is required, then the pull-down and hold-down voltages must be increased, and this can be done by increasing $g_{0}$ or the spring constant of the bridge. Another solution at $18 \mathrm{GHz}$ is to reduce the loading capacitance to $C_{D}=200 \mathrm{fF}$ (see Fig. 7). This will result in less standing waves and higher power handling, and can still match a $10 \Omega$ impedance at $18 \mathrm{GHz}$. However, if a wideband $6-18-\mathrm{GHz}$ matching network is needed, then one has to accept the fact that the network will handle more RF power at the low end of the band than at the high end.

\section{EXTENSION TO 4-ELEMENT NETWORKS}

A 4-element tuning network with 16 possible states was also developed for power-amplifier applications. The element values are exactly as Table 1 and the dimensions of the 4-element network are $1.9 \mathrm{~mm} \times$ $1.3 \mathrm{~mm}$ (see Fig. 3). The main advantage of this network is a reduced loss at the expense of less impedance coverage.

The measured impedance values with a $50 \Omega$ load agree very well with simulations over a wide frequency range (Fig. 19). The effect of the MEMS bridge capacitance $C_{U-M E M S}$, loading capacitance $C_{D}$, and separation $s$ are the same as the 8-element network and will not be repeated here. A detailed loss calculation based on the circuit model and the measured $S$-parameters shows a loss of $0.25-0.5 \mathrm{~dB}$ up to $12 \mathrm{GHz}$ and $1.0-1.5 \mathrm{~dB}$ at $18 \mathrm{GHz}$ for $10 \Omega$ and $20 \Omega$ loads (Fig. 20). The impedance match at these frequencies is around -15 to $-20 \mathrm{~dB}$, since the network results in only 16 possible combinations. Still, this is excellent for most power amplifiers operating at 4-18 $\mathrm{GHz}$.

Power measurements were also done on the 4-element network (Fig. 21). At 8 and $17.6 \mathrm{GHz}$, the network can handle at least +29 and $+31 \mathrm{dBm}$ of input power under a large range of $S_{11}$ and VSWR values. Notice that the TWT amplifier was unleveled and this explains the deviations in linearity even at low-RF input powers.

\section{CONCLUSION}

This article has presented a novel reconfigurable matching network based on 4- and 8-element loadedline networks for 4-18 GHz power amplifier applications. The 8-element network presents 256 impedance combinations, including a $50 \Omega$ impedance, and is also applicable for noise-parameter and load-pull measurement systems over a 3:1 frequency band. The 4-element network results in about $66 \%$ loss in the 8 -element design, but with a smaller impedance coverage (which can be a limitation if the both the PA and antenna impedances varies). Still, it may be an excellent design for PA applications driving a constant load. The designs are quite robust (especially the 8-element network), and can be easily scaled to $18-50 \mathrm{GHz}$ by reducing the loading capacitance and the switched-capacitor separation. It is possible that a 6-element network with 64 impedance points may ultimately be the best compromise between imped- 


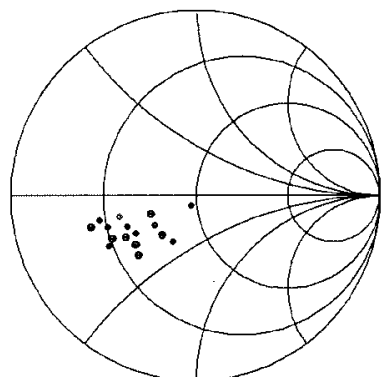

Measured $5.1 \mathrm{GHz}$

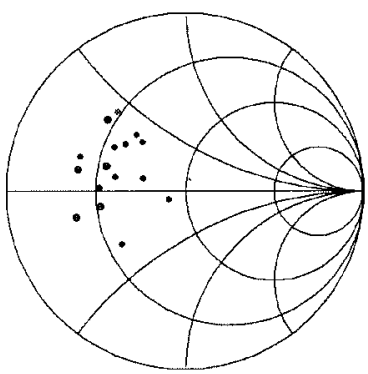

Measured $10.1 \mathrm{GHz}$

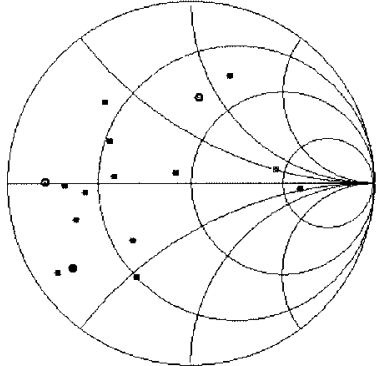

Measured $18.0 \mathrm{GHz}$

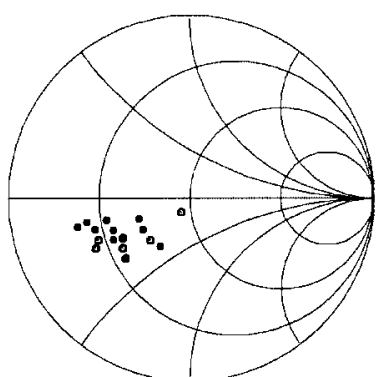

Simulated $5.1 \mathrm{GHz}$

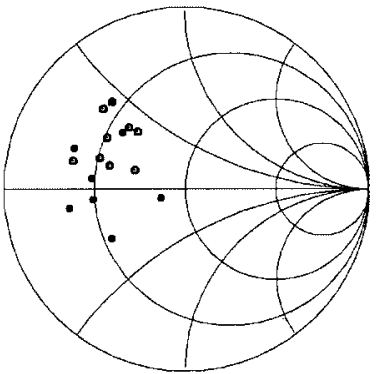

Simulated $10.1 \mathrm{GHz}$

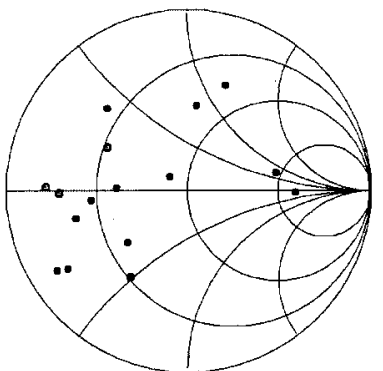

Simulated $18.0 \mathrm{GHz}$

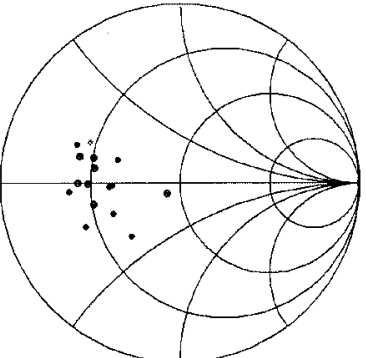

Measured $8.1 \mathrm{GHz}$

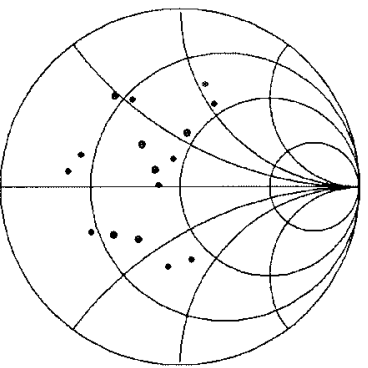

Measured 14.1 GHz

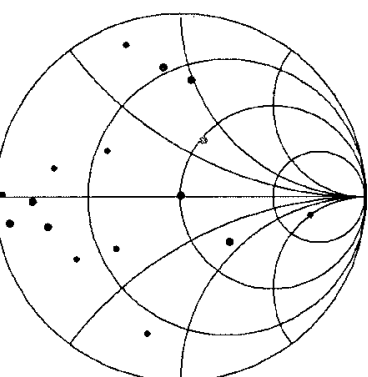

Measured $24.2 \mathrm{GHz}$

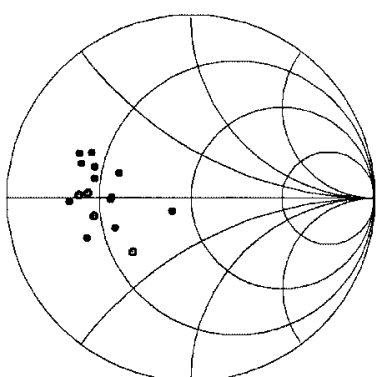

Simulated $8.1 \mathrm{GHz}$

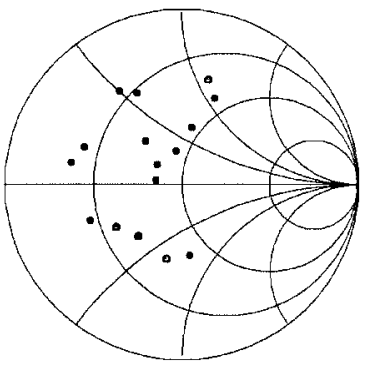

Simulated $14.1 \mathrm{GHz}$

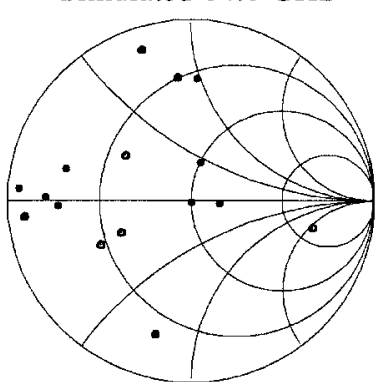

Simulated $24.2 \mathrm{GHz}$

Figure 19. Measured (16) and simulated (16) impedances of the 4-element reconfigurable MEMS matching network. The single-cell values are given in Table I.
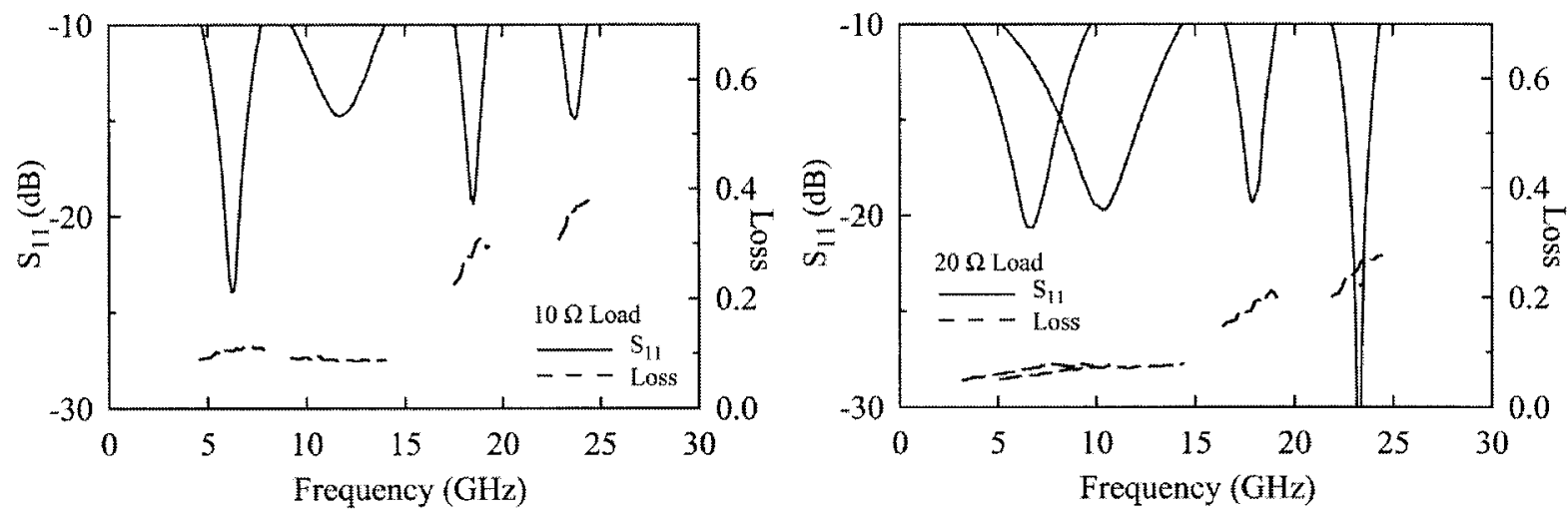

Figure 20. Input-reflection coefficient and loss obtained from measured $S$-parameters of the 4-element matching network with $10 \Omega$ and $20 \Omega$ loads. The $10 \Omega$ load is matched to $50 \Omega$ at $6 \mathrm{GHz}$ using (S1, S2,S3), at $12 \mathrm{GHz}(\mathrm{S} 3)$, at $18 \mathrm{GHz}(\mathrm{S} 1, \mathrm{~S} 2, \mathrm{~S} 3)$, and at $24 \mathrm{GHz}(\mathrm{S} 2, \mathrm{~S} 3)$. The $20 \Omega$ load is matched to $50 \Omega$ at $6 \mathrm{GHz}$ using (S1, S3), at $12 \mathrm{GHz}(\mathrm{S} 3)$, at $18 \mathrm{GHz}(\mathrm{S} 1, \mathrm{~S} 2, \mathrm{~S} 3)$, and at $24 \mathrm{GHz}$ $(\mathrm{S} 2, \mathrm{~S} 3)$. 

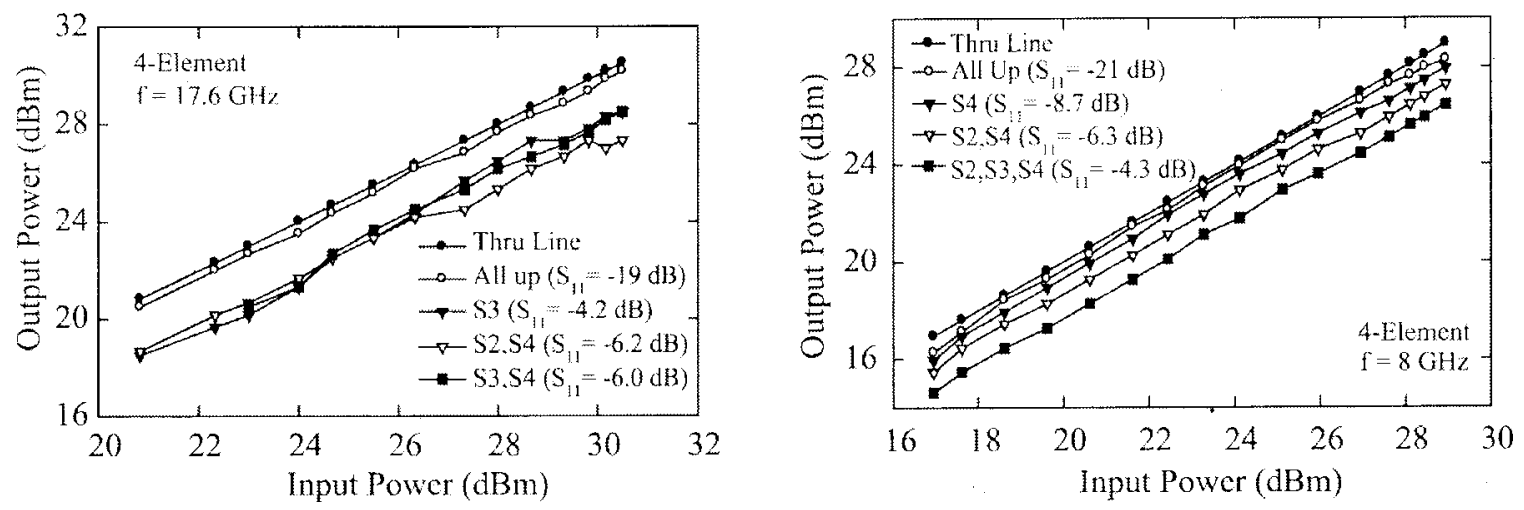

Figure 21. Power handling of the 4-element MEMS matching networks at 8 and $17.6 \mathrm{GHz}$ under different VSWR $\left(S_{11}\right)$ conditions.

ance flexibility and network loss in PA to antenna applications.

\section{ACKNOWLEDGMENTS}

This work was funded under the DARPA IRFFE program, under a subcontract from BAE; Dr. Edgar Martinez was Program Manager. The authors thank Donna Ryan and Richard Millard, BAE, for their technical inputs.

\section{REFERENCES}

1. N.S. Barker and G.M. Rebeiz, Optimization of distributed MEMS transmission line phase shifters - U-band and W-band designs, IEEE Transactions on Microwave Theory and Techniques, vol. 48, Nov. 2000, pp. $1957-$ 1966.

2. H.T. Kim, S. Jung, K. Kang, J.H. Park, Y.K. Kim, and Y. Kwon, Low-loss analog and digital micromachined impedance tuners at the Ka-band, IEEE Transactions on Microwave Theory and Techniques, vol. 49, pp. 2394 2400, Dec. 2001.

3. J. Papapolymerou, K.L. Lange, C.L. Goldsmith, A. Malczewski, and J. Kleber, Reconfigurable double-stub tuners using MEMS switches for intelligent RF frontends, IEEE Transactions on Microwave Theory and Techniques, vol. 51, pp. 271-278, Jan. 2003.

4. J.S. Hayden and G.M. Rebeiz, Very low-loss distrib- uted X-band and Ka-band MEMS phase shifters using metal-air-metal capacitors, IEEE Transactions on Microwave Theory and Techniques, vol. 51, Jan. 2003, pp. 309-314.

5. Y. Liu, A. Borgioli, A.S. Nagra, and R.A. York, K-band 3-bit low-loss distributed MEMS phase shifter, IEEE Microwave and Guided Wave Lett., vol. 10, Oct. 2000, pp. 415-417.

6. A. Abbaspour-Tamijani, L. Dussopt, and G.M. Rebeiz, Miniature and tunable filters using MEMS capacitors, IEEE Transactions on Microwave Theory and Techniques, vol. 51, July 2003, pp. 1878-1885.

7. Advanced Design System 2002, Agilent Technologies, Santa Clara, CA, USA, 2002.

8. R. E. Collin, Foundations for microwave engineering, $2^{\text {nd }}$ edition, New York, McGraw-Hill, 1992.

9. J.B. Rizk, W-band RF MEMS switches, phase shifters and antennas, Ph.D. dissertation, Dept. Elect. Eng. Univ. of Michigan at Ann Arbor, MI, 2003.

10. G.M. Rebeiz, RF MEMS theory, design, and technology, John Wiley \& Sons, New York, 2003.

11. L. Dussopt, G.M. Rebeiz, Intermodulation distortion and power handling in RF MEMS switches, varactors and tunable Filters, IEEE Transactions on Microwave Theory and Techniques, vol. 51, April 2003, pp. 12471256.

12. J.B. Rizk, E. Chaiban, G.M. Rebeiz, Steady state thermal analysis and high-power reliability considerations of RF MEMS capacitive switches, microwave symposium digest, IEEE MTT-S International Meeting, June 2, Seatle, WA, 2002, pp. 239-242. 


\section{BIOGRAPHIES}

Tauno Vähä-Heikkilä was born in Finland in 1977. He received his B.S. and M.S. degrees in Physics from the University of Turku in 2000 and 2001, respectively. From 2000 to 2001 he was a Trainee Research Scientist, and since 2001 has worked as a Research Scientist at the Millimeter Wave Laboratory of FinlandMilliLab, VTT TECHNICAL RESEARCH CENTER OF FINLAND. He was a Visiting Scholor at the Radiation Laboratory, the University of Michigan at Ann Arbor in 2002 and 2003. His research interests include development of reconfigurable RF MEMS circuits and millimeter wave on-wafer noise parameter and cryogenic measurements of active devices.
Gabriel M. Rebeiz (Fellow, IEEE) earned his Ph.D. degree in electrical engineering from the California Institute of Technology, Pasadena, and is a Full Professor of EECS at the University of Michigan, Ann Arbor. His research interests include applying microelectromechanical systems (MEMS) for the developemnt of novel RF and microwave components and sub-systems. He is also interested in Si RFIC design for radar and communication systems, and in the development of millimeter-wave front-end electronics planar antennas, imaging systems and phased-arrays.

Prof. Rebeiz was the recipient of the National Science Foundation Presidential Young Investigator Award in April 1991, and the URSI International Isaac Koga Gold Medal Award in August 1993. Prof. Rebeiz was selected by the students as the 1997-1998 EtaKappa-Nu EECS Professor of the Year. In October 1998, he received the Amoco Foundation Teaching Award, given yearly to one or two faculty at the University of Michigan, for excellence in undergraduate teaching. Prof. Rebeiz is the co-recipient, with Prof. Scott Barker, of the IEEE 2000 Microwave Prize. In 2003, he received the Outstanding Young Engineer Award of the IEEE MTT Society. Prof. Rebeiz is a Distinguished Lecturer for the IEEE MTT Society. 